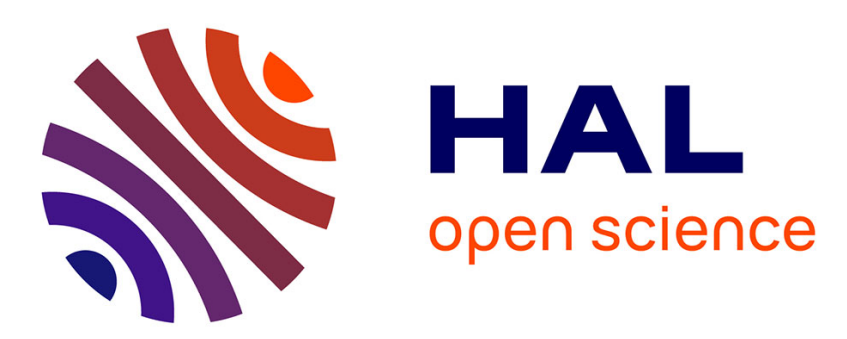

\title{
New Perspectives on Frontal Variability in the Southern Ocean
}

Christopher Chapman

\section{To cite this version:}

Christopher Chapman. New Perspectives on Frontal Variability in the Southern Ocean. Journal of Physical Oceanography, 2017, 47 (5), pp.1151 - 1168. 10.1175/JPO-D-16-0222.1 . hal-01685255

\section{HAL Id: hal-01685255 \\ https://hal.science/hal-01685255}

Submitted on 17 Nov 2021

HAL is a multi-disciplinary open access archive for the deposit and dissemination of scientific research documents, whether they are published or not. The documents may come from teaching and research institutions in France or abroad, or from public or private research centers.
L'archive ouverte pluridisciplinaire HAL, est destinée au dépôt et à la diffusion de documents scientifiques de niveau recherche, publiés ou non, émanant des établissements d'enseignement et de recherche français ou étrangers, des laboratoires publics ou privés.

\section{(c)(1)}

Distributed under a Creative Commons Attribution| 4.0 International License 


\title{
${ }^{\partial}$ New Perspectives on Frontal Variability in the Southern Ocean
}

\author{
CHRISTOPHER C. CHAPMAN \\ LOCEAN-IPSL, Université de Pierre et Marie Curie, Paris, France
}

(Manuscript received 29 September 2016, in final form 1 March 2017)

\begin{abstract}
The frontal structure of the Southern Ocean is investigated using the Wavelet/Higher Order Statistics Enhancement (WHOSE) frontal detection method, introduced in Chapman's work. This methodology is applied to $21 \mathrm{yr}$ of daily gridded absolute dynamic topography (ADT) data to obtain daily maps of the locations of the fronts. By forming frontal occurrence frequency maps and then approximating these occurrence maps by a superposition of simple functions, the time-mean locations of the fronts, as well as a measure of their capacity to meander, are obtained and related to the frontal locations found by previous studies. The spatial and temporal variability of the frontal structure is then considered. The number of fronts is found to be highly variable throughout the Southern Ocean, increasing (splitting) downstream of large bathymetric features and decreasing (merging) in regions where the fronts are tightly controlled by the underlying topography. These splitting/merging events are related to changes in the underlying frontal structure whereby regions of high frontal occurrence cross or spread over streamfunction contours. In contrast to the number of fronts, frontal meandering remains relatively constant throughout the Southern Ocean. Little to no migration of the fronts over the 1993-2014 time period is found, and there is only weak sensitivity of frontal positions to atmospheric forcing related to the southern annular mode or the El Niño-Southern Oscillation. Finally, the implications of these results for the study of cross-stream tracer transport are discussed.
\end{abstract}

\section{Introduction}

Observations dating back to the Discovery expedition have revealed that the Antarctic Circumpolar Current (ACC) is composed of large-scale hydrographic fronts (Deacon 1937). Although it is difficult to give a precise definition of a front (Langlais et al. 2011; Chapman 2014), they are generally considered to be regions where water mass properties change rapidly (Sokolov and Rintoul 2002). In the Southern Ocean, fronts are aligned more or less zonally. Water mass properties change rapidly across the front, yet remain approximately constant along the front (Deacon 1937; Orsi et al. 1995; Belkin and Gordon 1996). These studies have led to the traditional view (Langlais et al. 2011) that the Southern Ocean is composed of three circumpolar hydrographic fronts that are (from north to south) the Subantarctic

¿ Denotes content that is immediately available upon publication as open access.

Corresponding author: C. C. Chapman, chris.chapman.28@ gmail.com
Front (SAF), the Polar Front (PF), and the Southern ACC Front (SACCF).

Southern Ocean fronts are thought to be closely related to strong zonal geostrophic jets (Gille 1994; Sokolov and Rintoul 2007), and it has been shown that jets and hydrographic fronts are often collocated (Sokolov and Rintoul 2002). However, there is evidence from highresolution satellite data and numerical modeling that these jets are not smooth, continuous circumpolar features but are instead complicated mesoscale phenomena that split, merge, and drift and that their structure varies in both space and time (Hughes and Ash 2001; Hallberg and Gnanadesikan 2006; Thompson 2010; Thompson et al. 2010; Hughes et al. 2010; Chapman 2014). The relationship of these smaller-scale, braided jets to the three traditional hydrographic fronts is still unclear, as the small-scale jets are not always coincident with the high in situ density gradients that denote the hydrographic fronts (Graham et al. 2012; Chapman 2014). Despite this complication, the terms jet and front are often used interchangeably. Southern Ocean fronts can influence the upwelling and ultimate ventilation of deep waters, which can in turn affect the formation of water masses at the surface (Böning et al. 2008; Meijers et al. 2012; 
Meijers 2014) and can act to suppress the meridional exchange of tracers (Shuckburgh et al. 2009; Ferrari and Nikurashin 2010; Thompson and Sallée 2012; Foppert et al. 2016). Frontal anomalies could also result in anomalous water mass properties being redistributed throughout the ocean by the strong zonal currents that compose the ACC (Sallée et al. 2008).

Multiple studies using either satellite data alone (Sokolov and Rintoul 2009b; Billany et al. 2010) or a mix of satellite and hydrographic data (Sallée et al. 2008; Tarakanov and Gritsenko 2014; Kim and Orsi 2014) have identified large meridional shifts in the locations of fronts, sometimes as large as $10^{\circ}$ of latitude, with temporal variability being concentrated in regions away from large bathymetric features that act to constraint frontal locations. Both Sallée et al. (2008) and Kim and Orsi (2014) find significant correlation between the southern annular mode (SAM) and the El Niño-Southern Oscillation (ENSO) and the position of the fronts in the southeast Indian and southeast Pacific basins. In contrast, studies using similar data yet different methods yield contrary results, showing no coherent trends in frontal location (Graham et al. 2012; Gille 2014; Shao et al. 2015; Freeman et al. 2016), although these studies do not rule out localized or higher-frequency variability such as the meridional "drift" of jets identified by Thompson and Richards (2011) or "jet jumping" (Chapman and Hogg 2013; Chapman and Morrow 2014).

The root of this controversy appears to stem from the definition of a front. The contour methods, introduced in Sokolov and Rintoul (2002) and used in the majority of studies that find long-term trends in frontal positions, exploit the fact that regions of high sea surface height (SSH) gradient (that define a strong geostrophic current) are often collocated with a unique value of SSH. Thus, any shift in the location of that contour will logically correspond to a shift in the front. In contrast, the majority of studies that find little or no change in frontal position define fronts based on local criteria such as SSH gradients (Graham et al. 2012; Gille 2014; Shao et al. 2015). Contour methods have recently been criticized by Thompson et al. (2010) and Graham et al. (2012), who show that the unique value of SSH selected to designate a front may not always coincide with the regions of high SSH gradients, which can result in spurious temporal variability. Additionally, as noted by Langlais et al. (2011), when using contour-type definitions, there is no agreed upon number of fronts in the Southern Ocean. However, contour methods perform well when used to detect the time-mean positions of fronts (Langlais et al. 2011; Graham et al. 2012; Chapman 2014) and have great value when used to define a coordinate system for along and across-front transport calculations (Dufour et al. 2015). For more detail and further comparisons between these methods, see Chapman (2014).

The goals of this paper are to study in detail the spatial and temporal variability of the frontal structure of the Southern Ocean and to investigate the response of fronts to changes in atmospheric forcing associated with the SAM and ENSO by applying the Wavelet/ Higher Order Statistics Enhancement (WHOSE) methodology, introduced in Chapman (2014), to $21 \mathrm{yr}$ of altimetric sea surface dynamic topography data. The WHOSE method is a local method that allows the number of fronts to vary both spatially and temporally. By forming and further approximating maps of frontal occurrence frequency as a superposition of simple functions to avoid the difficulty of tracking individual frontal filaments, we will analyze how the frontal structure changes geographically and robustly determine temporal trends in the frontal location, making no assumptions regarding the number of fronts or their geographical extent. In doing so, we will link the complex, small-scale fronts detected by the WHOSE method to the traditional hydrographic fronts and determine the sensitivity of the frontal positions to changes in the SAM and ENSO.

The remainder of this paper is organized as follows: Section 2 will briefly discuss the frontal detection methodology (the WHOSE method) and describe the data to be used. Section 3 will focus on the time-mean frontal structure and its spatial variability. Trends in frontal locations and their sensitivity of changes in atmospheric forcing will be presented in section 4 . Finally, section 5 discusses the implications of this work and makes a number of recommendations for future studies pursuing this subject.

\section{Data and methodology}

\section{a. Data}

\section{1) TIME-MEAN DYNAMIC TOPOGRAPHY}

To estimate the mean state of the ocean, we use the mean dynamic topography (MDT) product (Rio et al. 2014), downloaded from the CNES Collecte Localisation Satellites (CLS) (CLS 2013). The mean sea surface is reconstructed over the period 1993-2012 by combining data from the Gravity Recovery and Climate Experiment (GRACE) mission, satellite altimeters, drifting buoys, in situ hydrographic observations, and surface wind stress from the ERA-Interim reanalysis project.

\section{2) TIME-VARYING DYNAMIC TOPOGRAPHY}

The satellite dataset used in this study is the Archiving, Validation, and Interpretation of Satellite 
Oceanographic (AVISO) daily gridded sea level anomalies (SLA) from Ssalto/Duacs, downloaded from Copernicus Marine Services (Ssalto/Duacs 2014; Pujol et al. 2016). We use delayed-mode dynamic topography for the period 1993-2015, with daily output, giving 8035 data records. These data are mapped to a $1 / 4^{\circ}$ Mercator grid using optimal interpolation of along-track data series based on the REF dataset, which uses two satellite missions [Ocean Topography Experiment (TOPEX)/Poseidon/European Remote Sensing Satellite (ERS) or Jason-1/Envisat or Jason-2/Envisat] with consistent sampling over the 21-yr period. Data are corrected for instrumental errors, atmospheric perturbations, orbit errors, tides, inverted barometer bias, and aliased fast barotropic signals (periods of less than 20 days). Although the output grid spacing is $1 / 4^{\circ}$, the effective resolution is actually set by the correlation length scales used in the optimal interpolation (in the Southern Ocean approximately $15 \mathrm{~km}$ in the meridional direction, $100 \mathrm{~km}$ in the zonal direction) and the underlying resolution of the along-track data, which is filtered to remove wavelengths smaller than $65 \mathrm{~km}$ (Pujol et al. 2016). With increasing horizontal resolution, such as the 50to $100-\mathrm{m}$ resolution, which will be available with the launch of the Surface Water and Ocean Topography (SWOT) satellite (http://smsc.cnes.fr/SWOT), tighter front spacing and hence more accurate determination of the number of fronts and their meander amplitudes may be possible.

This study uses ADT, which is the sum of the timemean dynamic topography and time-varying sea level anomalies.

\section{3) SOUTHERN ANNULAR MODE AND EL NIÑO-SOUTHERN OSCILLATION INDIES}

The leading modes of atmospheric variability over the Southern Ocean are generally considered to be the SAM and ENSO. To investigate the response of Southern Ocean fronts to changes in these climate modes, we obtained the monthly SAM index, described in Marshall (2003a), from the British Antarctic Survey (Marshall 2003b) and the monthly bivariate ENSO time series (Smith and Sardeshmukh 2000a) from the NOAA Earth Systems Research Laboratory (Smith and Sardeshmukh 2000b). Both time series are then low-pass filtered with a finite impulse response Blackman filter with a cutoff period of 3 months.

\section{b. Front detection methodology}

Here, we will briefly describe the WHOSE methodology used to detect fronts in this study. The WHOSE method was originally developed by Chapman (2014), inspired by methods used for the detection of steplike signals in acoustic and radar data. Further details, including implementation notes, extensive validation, and a detailed comparison with other methods, are found in Chapman (2014).

The WHOSE method belongs to the broader class of local gradient maxima methods. As their name implies, these methods identify fronts by finding points where the gradient of SSH, SST, or similar quantities exceeds a predefined threshold. Studies using these methods have revealed that the Southern Ocean hosts an intricate web of interleaving fronts that are not necessarily circumpolar in extent (Moore et al. 1999; Hughes and Ash 2001; Kostianoy et al. 2003; Burls and Reason 2006; Dong et al. 2006; Billany et al. 2010; Graham et al. 2012). However, oceanic eddies can induce SSH and SST gradients of similar or even greater magnitude than those associated with fronts. As differentiation (required to compute the gradient) tends to amplify "noise," locally distinguishing between eddies and fronts is a difficult task and some kind of filtering or averaging should be employed.

The WHOSE method reduces the influence of eddies and other noise by using a denoising filter that specifically searches for steplike signals that are the manifestation of oceanic fronts in SSH or SST by exploiting the fact that step signals have nonzero kurtosis:

$$
K(x)=\frac{\mathbb{E}\left[(x-\bar{x})^{4}\right]}{\left\{\mathbb{E}\left[(x-\bar{x})^{2}\right]\right\}^{2}}-3,
$$

where $x$ is a real random variable, $\mathbb{E}$ denotes the expectation operator, and the overbar denotes the mean (Ravier and Amblard 1998). If the noise introduced by differentiation is assumed to have a normal distribution (hence zero kurtosis) and the steplike signal is nonnormal (nonzero kurtosis) then a kurtosis criteria should be able to separate the signal from the noise.

The algorithm has four primary steps:

Step 1: Perform a wavelet decomposition in the space domain in order to decompose the ADT into scales.

Step 2: At each wavelet scale, we determine if those coefficients are normally distributed, and hence noise or nonnormal, and therefore signal by determining if the kurtosis of the wavelet coefficients falls within bounds given by the Bienaymé-Chebyshev inequality [see Chapman (2014, p. 4323), his Eq. (4)]. If the wavelet coefficients at that scale are found to be noise, then they are set to zero. Otherwise, they are retained without modification.

Step 3: For the remaining wavelet coefficients, apply the spatially adaptive wavelet denoising procedure of Donoho and Johnstone (1995). Wavelet 


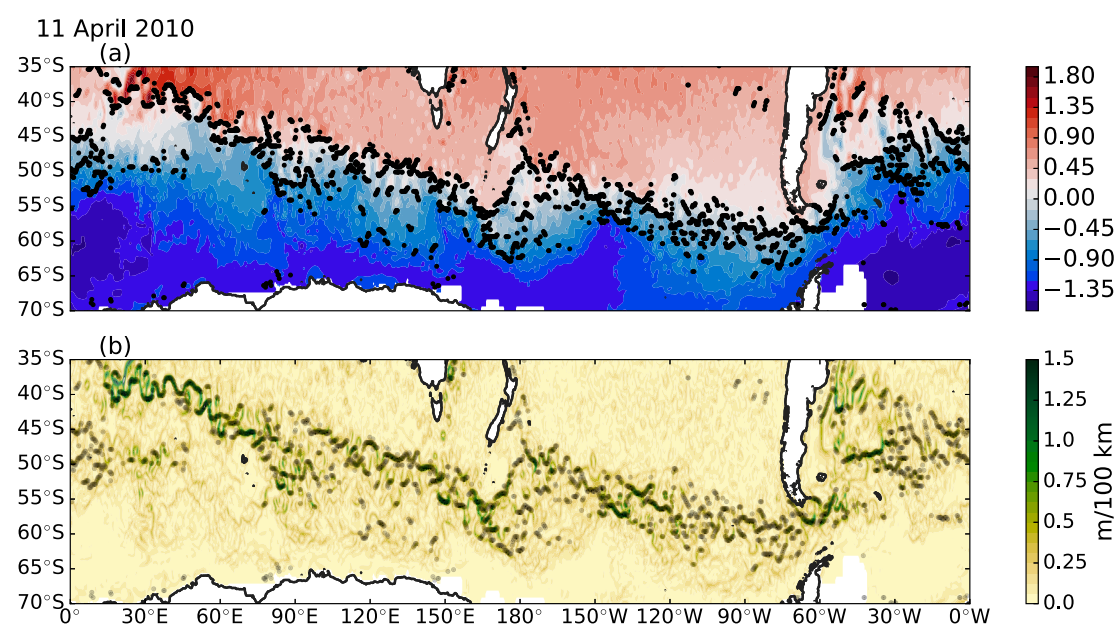

FIG. 1. Snapshot of the (a) ADT and (b) ADT gradient on 11 Apr 2010, overlaid with the locations of the detected fronts (black dots). Note that detected fronts outside of the Southern Ocean latitudes have been removed from the analysis (see text for details).

coefficients are set to zero where they are less than a threshold $\lambda$, given by

$$
\lambda^{s}=\operatorname{median}\left[\left|d^{s}(x, t)\right|\right] \sqrt{2 \log _{10} N} / 0.6745,
$$

where $s$ denotes the wavelet scale, $d$ is the wavelet detail coefficients at scale $s$, and $N$ is the number of points on the transect. The general idea is that the signal is contained only in the large-amplitude wavelet coefficients, while the noise is contained in the small-amplitude coefficients, but that amplitude of the noise may vary depending on the spatial scale. This procedure effectively removes white noise while taking into account the local spatial scale of the signal.

Step 4: The inverse wavelet transform is used to reconstruct the SSH transect, and gradient thresholding is applied to determine the front locations. Following Graham et al. (2012), the gradient threshold is set to $0.1 \mathrm{~m}$ per $100 \mathrm{~km}$. Sensitivity tests to variations of this parameter have been performed and are included in appendix $\mathrm{C}$.

This algorithm has been implemented in the opensource Python language, and the code is freely available from the author's Github repository (see appendix A).

The advantage of the WHOSE method is that by filtering the noise induced by eddies and other smallscale motions, front positions can be determined from instantaneous snapshots of ADT, even in regions of high eddy activity. In comparison, naive gradient thresholding (i.e., without the filtering steps) is unable to reliably detect fronts in regions with intense eddy activity due to a large number of false positive errors (Chapman 2014), and methods such as the skewness/ kurtosis criteria of Hughes et al. (2010) and Shao et al. (2015) require taking time averages over long time periods [the shortest time period analyzed by Shao et al. (2015) is $1 \mathrm{yr}$ ] and, as such, can smooth out smallscale or ephemeral features. The fronts we seek are mesoscale features, with across-front scales of $\sim 80 \mathrm{~km}$ being detected by both the WHOSE method (Chapman 2014) and the skewness/kurtosis criteria methods (Shao et al. 2015).

The WHOSE method is applied to each daily ADT map between $70^{\circ}$ and $30^{\circ} \mathrm{S}$, producing 8035 daily maps of frontal location. An example is shown in Fig. 1, along with a snapshot of the ADT (Fig. 1a) and |VADT| (Fig. 1b). We see that frontal locations (circles) follow large yet zonally coherent ADT gradients. These daily maps of frontal location have been made freely available for download (see appendix B).

The detected fronts show significant nonzonal orientation, primarily due to the steering of the flow by subsurface topography (e.g., between $150^{\circ} \mathrm{E}$ and $180^{\circ}$ at the Campbell Plateau) or high-frequency variability induced by Rossby waves moving along the fronts, as described by Hughes (1996), mostly clearly seen in the Agulhas region, south of Africa (between $20^{\circ}$ and $50^{\circ} \mathrm{E}$ ). Animations of frontal location indicate substantial highfrequency variability, including the aforementioned Rossby wave propagation as well as the drift, splitting, and merging identified in the idealized experiments conducted by Thompson (2010).

In contrast to Shao et al. (2015), who uses the alongtrack AVISO product, we employ the gridded product in this study. Since the use of optimal interpolation for 
gridding the along-track data does modify the statistics of the ADT field, including the kurtosis (Sura and Gille 2010), we have repeated the analysis on the AVISO along-track ADT for a single year: 2010. We find that the frontal positions obtained using the along-track data are very similar to those obtained using the gridded product for a similar set of parameter choices, although because of the different grid spacing, the frontal positions are not identical. However, the differences are minor (generally less than one grid point), which is consistent with the analysis of ADT statistics by Sura and Gille (2010).

\section{c. Determination of mean frontal positions and meandering amplitude}

As implied by Fig. 1, the WHOSE method produces frontal location maps that are essentially a threedimensional (latitude, longitude, and time) array of bits, where a "true" value indicates the presence of a front at that particular time and location. In contrast to contour methods, fronts defined in this way may not be present at all longitudes and at all times. The number of fronts present at any particular longitude ranges from as few as two (e.g., between longitudes $120^{\circ}$ and $150^{\circ} \mathrm{E}$, south of Tasmania) to as many as 15 (e.g., between about $65^{\circ}$ and $30^{\circ} \mathrm{W}$, downstream of Drake Passage).

To investigate the time-mean behavior of the fronts and their meandering, we form maps of frontal occurrence frequency (a kind of 2D histogram or occurrence map) by counting the number of times a front is found at each point in the domain over a certain time period. A sharp, localized peak in the occurrence map indicates the presence of a persistent front with little time variability, while a more broad distribution of points around a peak indicates a meandering front.

Occurrence maps provide a qualitatively attractive framework for understanding the ACC's frontal system. However, making robust quantitative arguments based on these maps is more difficult. To tackle this problem, we fit to each meridional transect of the occurrence map an arbitrary number of skew normal functions (Azzalini and Capitanio 1999):

$$
f_{j}\left(\phi ; A, \bar{\phi}_{j}, \sigma, \gamma\right)=A e^{-(\phi-\bar{\phi})^{2} /\left(2 \sigma^{2}\right)}\left\{1+\operatorname{erf}\left[\frac{\gamma\left(\phi-\bar{\phi}_{j}\right)}{\sqrt{2} \sigma}\right]\right\},
$$

where erf is the error function, $A$ is the amplitude, $\bar{\phi}_{j}$ is the mean latitude, $\sigma$ is the standard deviation, $\gamma$ is the skew parameter, and $j \in \mathbb{Z}$ is the frontal index. The functions are fitted by nonlinear regression. Skew normal curves differ from a standard normal curve by the presence of asymmetry, measured by the skew parameter $\gamma$. A positive (negative) $\gamma$ results in an elongated tail to the right (left) of the mean. We have chosen to use a skew normal function, in lieu of a standard normal function, because the occurrence maps show some asymmetry in certain regions, with the front being more likely to drift or meander to one side of the mean position than another. An example of this effect, the spontaneous drifting and reforming of fronts, was identified by Thompson and Richards (2011).

At each longitude $\lambda$, the frontal occurrence map is approximated as

$$
P(\lambda ; \phi)=\sum_{i=0}^{n} f_{i}\left(\phi ; A_{i}, \bar{\phi}_{i}, \sigma_{i}, \gamma_{i}\right) .
$$

Each component function $f_{i}$ shall be interpreted as a separate front at that longitude. To determine the number of fronts $n$, we use the Akaike information criterion (AIC; Akaike 1974; Burnham et al. 2011), which for an occurrence map transect modeled by the sum of $m$ skewed normal functions, is

$$
\mathrm{AIC}_{m}=8 m+\log \mathscr{b},
$$

where $\mathscr{B}$ is the maxima of the likelihood function (a measure of the goodness of fit of the model to the data). The AIC quantifies the trade-off between how well a model fits the data and the complexity, measured by the number of parameters in the model. A model with a lower AIC is preferred. The $8 m$ term in Eq. (5) effectively penalizes fitting additional functions (hence another frontal peak). The AIC is used as a means of model selection because of its simplicity, relative computational efficiency (when compared to cross validation), and its relative ease of implementation when employed alongside nonlinear regression. We have also tested using the Bayesian information criterion (BIC) as the means of model selection and found only minor differences in the result. Starting with $n=1$, additional skew normal components are added until the AIC reaches a local minima. The value of $n$ that minimizes the AIC is taken as the number of fronts at that longitude.

\section{d. Spatiotemporal frontal variability in a toy model}

Before discussing the complicated flow structure in the Southern Ocean, we use a simple toy problem to illustrate some aspects of the frontal occurrence maps. Consider a meandering front with a meridional position $y$ decomposed into a mean component $\bar{y}$ (that is possibly spatially variable) and a meandering $y^{\prime}$ component:

$$
y(x ; t)=\bar{y}(x)+y^{\prime}(x ; t),
$$

where $x$ is the zonal coordinate, and $t$ is time. Here, $\overline{y^{\prime}}=0$, with the overline indicating the mean value. The 


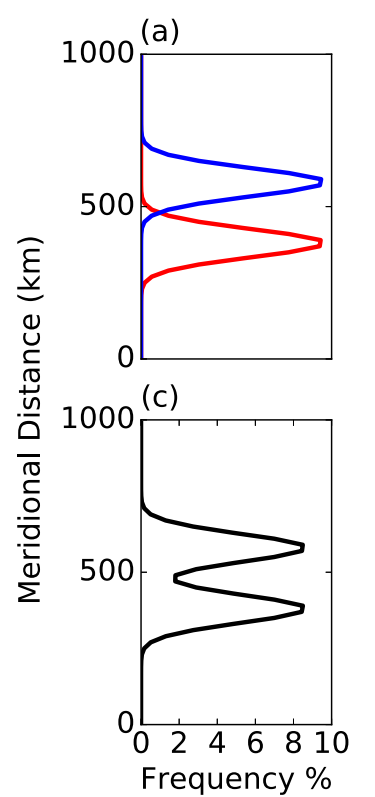

(b)

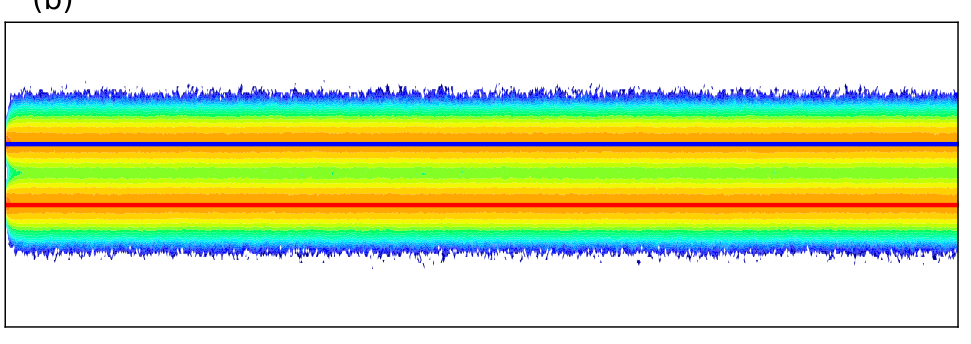

(d)
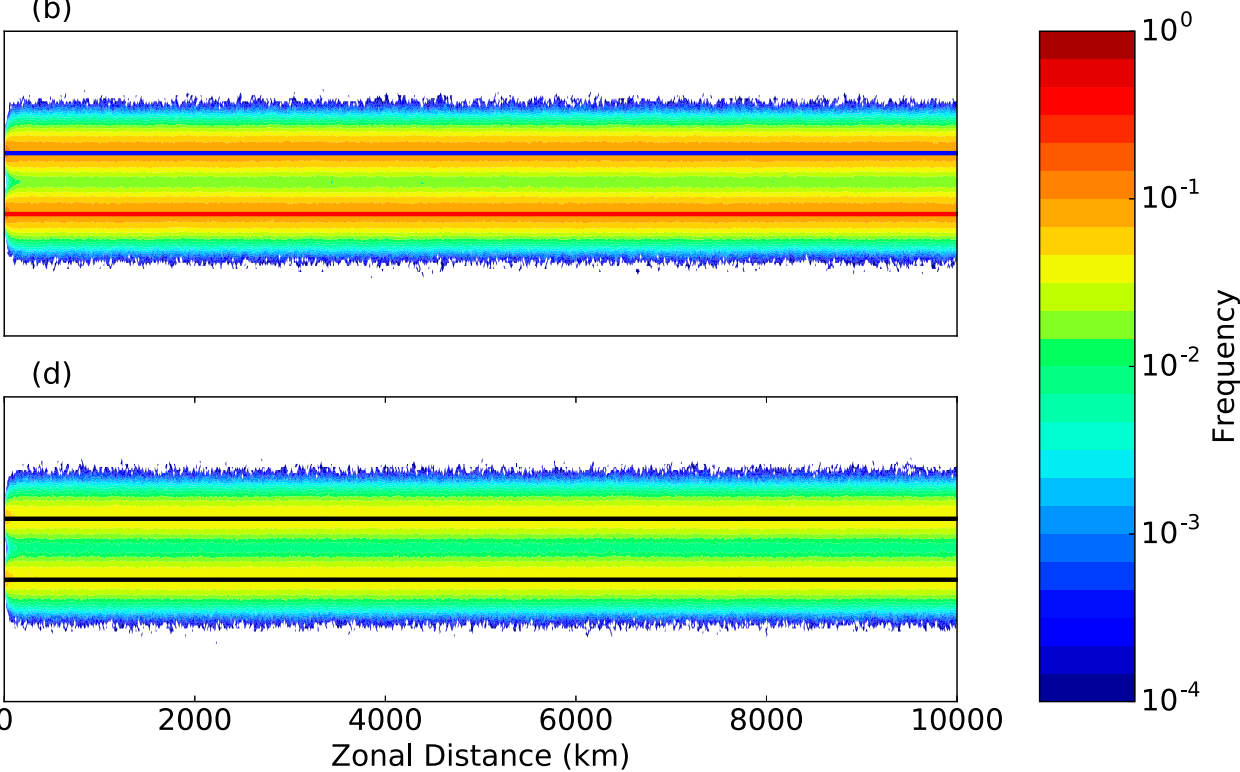

FIG. 2. Multiple fronts vs a single bistable front in a toy model. (a) The meridional position PDFs for two synthetic fronts centered at $y=$ 400 and $600 \mathrm{~km}$. (b) The (normalized) frontal frequency of occurrence map for the situation with two stochastically meandering fronts. The blue (red) solid lines indicate the mean frontal positions. (c) The meridional position PDFs for a single synthetic front with two stable positions $(y=400$ and $600 \mathrm{~km})$ and (d) the (normalized) frontal frequency of occurrence maps for the single bistable front situation. The black solid lines indicate the mean positions of the two fronts.

meandering component $y^{\prime}$ is modeled as a spatially autocorrelated first-order autoregressive process [AR(1)] stochastic process:

$$
y^{\prime}\left(x_{i+1} ; t\right)=\rho y^{\prime}\left(x_{i} ;\right)+\varepsilon,
$$

where $\rho=0.9$ is the autocorrelation parameter, and $\varepsilon \sim \mathscr{N}\left(0, \sigma^{2}\right)$ is the uncorrelated white noise drawn from a normal distribution with zero mean and a standard deviation $\sigma=\sigma(x)$ that can vary spatially.

Occurrence maps generated from 10000 realizations of the toy problem are shown in Fig. 2 for two different situations: two fronts that meander about constant mean meridional positions $\bar{y}_{1}=400 \mathrm{~km}$ and $\bar{y}_{2}=600 \mathrm{~km}$ (Figs. 2a,b) and a single meandering bistable front with two preferred mean locations at 400 and $600 \mathrm{~km}$. In the latter case, the front randomly flips between the two mean positions, as in Chapman and Hogg (2013). In both cases, the standard deviation $\sigma$ of the meandering component is a constant $25 \mathrm{~km}$. We see in Figs. $2 \mathrm{a}$ and $2 \mathrm{~b}$ that the occurrence maps produced are virtually indistinguishable, despite the different underlying frontal structures that have been used to produce them. As such, we note that our occurrence map method is unable to distinguish between an ephemeral front that changes its location or two stable, neighboring fronts. However, as noted by Chapman and Morrow (2014), the fronts that exhibit bistable behavior are somewhat rare in the
Southern Ocean. As such, herein we interpret two adjacent peaks in an occurrence map as indicating two different fronts and not a single ephemeral front undergoing jet jumping.

We now consider two different cases of spatial variability: a splitting/merging case (Figs. 3a,b), where a single front with a constant meandering amplitude of $\sigma=25 \mathrm{~km}$ splits at a particular location into two distinct fronts (indicated by the solid lines in Fig. 3b) before merging again, and a variable meandering case (Figs. 3c,d): a single front with a spatially varying meander amplitude that has the form

$$
\sigma(x)=A_{v} \cos \left(\frac{\pi}{L_{x}} x\right)+A_{0},
$$

where $A_{0}=10 \mathrm{~km}$ is the constant background meandering amplitude, and $A_{v}=150 \mathrm{~km}$ is the spatially varying meander amplitude (shown in Fig. 3e).

The occurrence maps shown in Fig. 3 for the splitting/ merging case have a very different structure than those for the meandering front case. For the splitting/merging case, the occurrence map broadens and reduces in magnitude after the splitting event. Additionally, after the splitting occurs (indicated by the arrow in Fig. 3b), there is a transition from a single peak in the occurrence map to two clearly defined peaks separated by minima, with the reverse occurring where the fronts merge. 


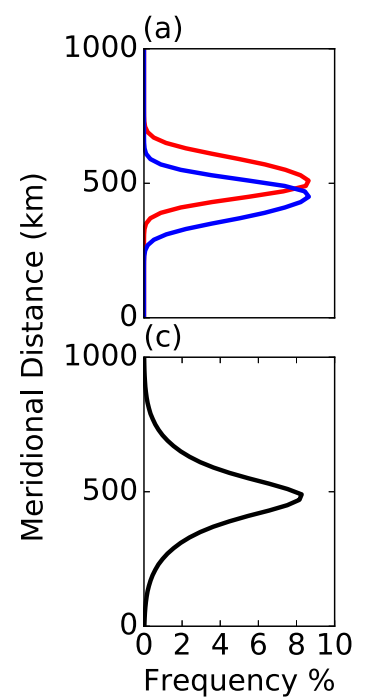

(b)

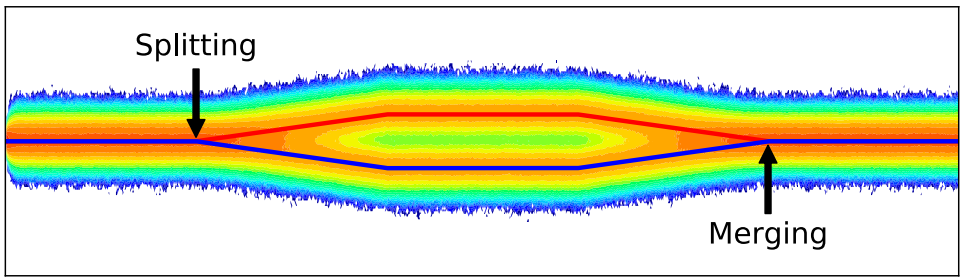

(d)
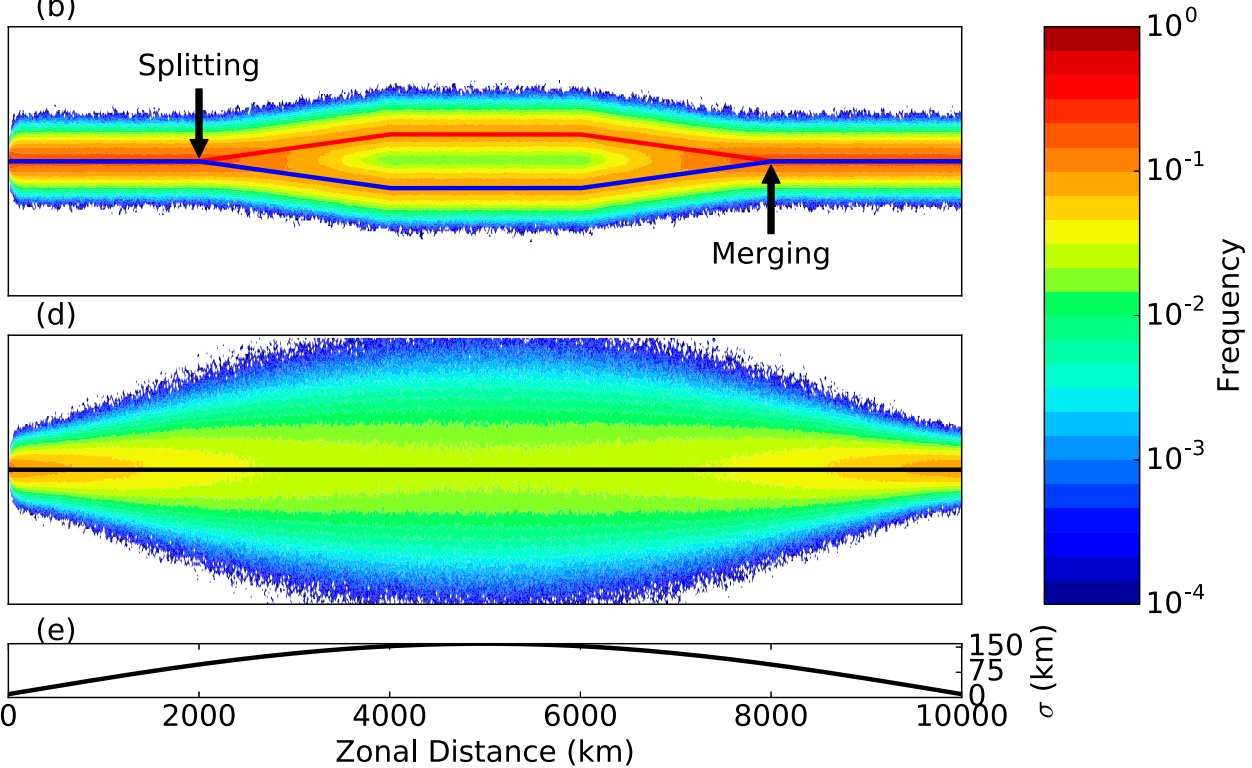

FIG. 3. Splitting/merging compared with variable meandering in a toy model. (a) The meridional position PDFs for two synthetic fronts that undergo splitting and merging. The red (blue) line indicates the front that splits to the north (south). (b) The (normalized) frontal frequency occurrence maps for synthetic fronts that split and merge. Solid red (blue) line indicates the mean front position. (c) As in (a), but for a single front with an increasing then decreasing meander amplitude. (d) As in (b), but for the single front with increasing then decreasing meandering amplitude. (e) The spatial variation of the standard deviation $\sigma$ of the front in (c) and (d), defined in Eq. (8).

Similarly, in the variable meandering case the occurrence map broadens and reduces in amplitude as $\sigma$ increases. However, there is no development of an additional peak in the occurrence map. As such, we can distinguish between splitting/merging and variable meandering with knowledge of two key parameters: the meander amplitude, measured by $\sigma$, and the number of peaks in the occurrence map at any particular longitude.

\section{Time-mean frontal behavior}

The Southern Ocean is zonally asymmetric. Mesoscale activity and the primary orientation of the mean flow both vary with longitude (Rintoul and NaveiraGarabato 2013). Bathymetry, which both steers the ACC currents and acts to generate regions of intense turbulence, is thought to influence fronts in two ways: first, fronts that pass over regions with large gradients in bottom topography are constrained in their movement and capacity to meander (Sokolov and Rintoul 2009b); and second, since mesoscale turbulence is generated preferentially in regions downstream of large bathymetric features (Williams et al. 2007; Chapman et al. 2015), it has also been suggested that fronts may show increased variability in these regions (Langlais et al. 2011; Chapman 2014). However, there is some disagreement about how this variability manifests: Langlais et al. (2011) suggests coherent meandering of the fronts, while Chapman (2014) provides evidence of fronts splitting into additional smaller-scale subfronts in these regions. In this section, we use the WHOSE fronts together with the nonlinear fitting procedure to investigate how the structure and meandering of fronts varies throughout the Southern Ocean.

\section{a. Frontal occurrence frequency and time-mean positions}

The occurrence map obtained from the WHOSE method for the period 1993-2015 is shown in Fig. 4a, which reveals a complicated frontal structure that changes throughout the Southern Ocean. In certain regions, for example, south of Australia (between about $90^{\circ}$ and $130^{\circ} \mathrm{E}$; Fig. $4 \mathrm{a}$, box i), the occurrence maps indicate one or two strongly persistent fronts. Other regions, for example, near the Campbell Plateau south of New Zealand $\left(170^{\circ} \mathrm{E}\right.$ to $170^{\circ} \mathrm{W}$; Fig. $4 \mathrm{a}$, box ii), show multiple persistent fronts with clear peaks in the occurrence map but with a broad distribution of points about those peaks, more indicative of meandering fronts. Finally, there are regions, such as the eastern Pacific $\left(90^{\circ} \mathrm{W}\right.$ to $70^{\circ} \mathrm{E}$; Fig. $4 \mathrm{a}$, box iii), where the frontal structure consists of a broad distribution of points with no dominant peak, indicative of either strongly meandering fronts or numerous, closely packed fronts. The later region corresponds to that identified by Thompson et al. (2010), where the interior potential 


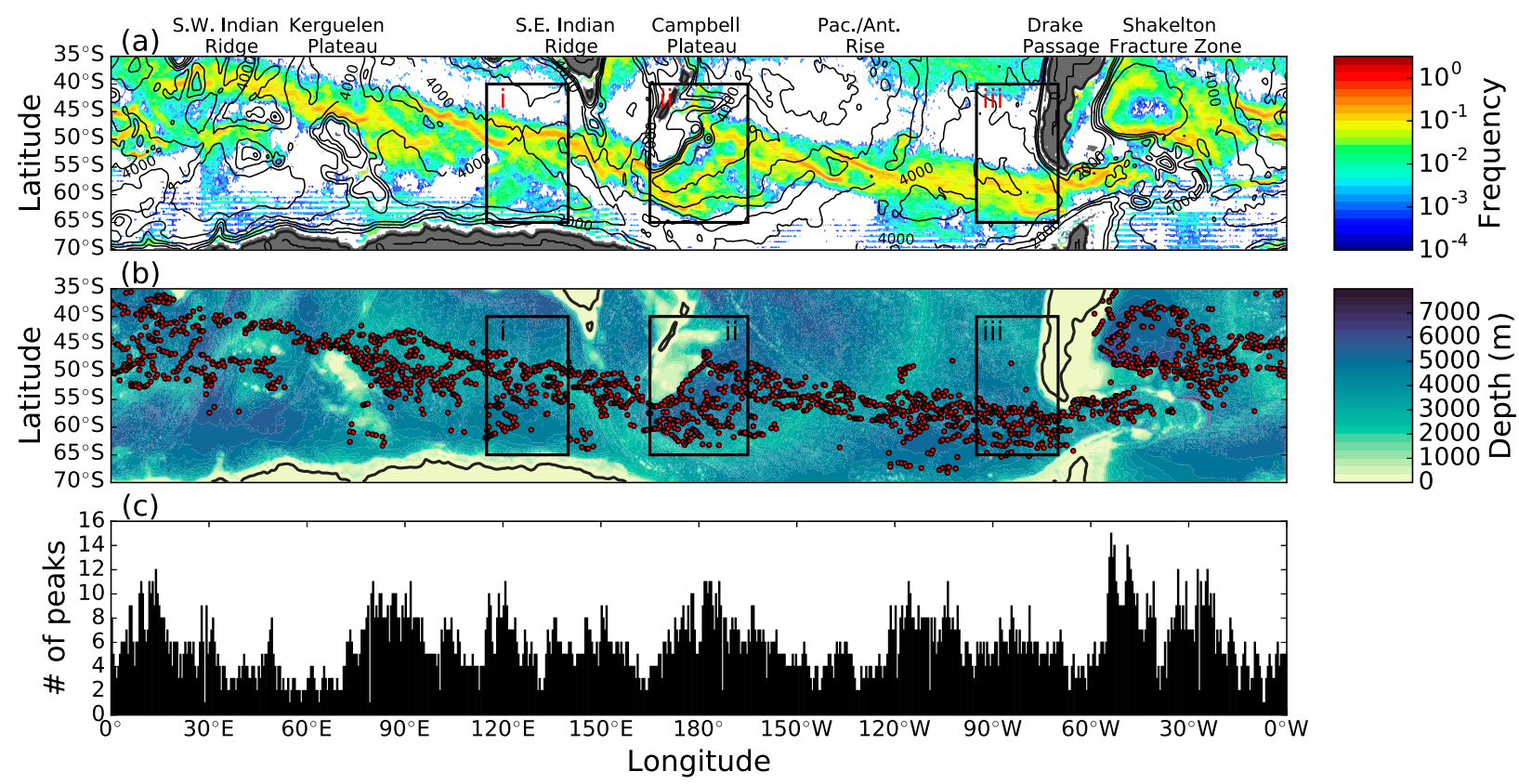

FIG. 4. The time-mean structure of the Southern Ocean fronts. (a) The (normalized) frontal frequency of occurrence maps for the period 1993-2015 (note the logarithmic color scale); (b) the time-mean frontal locations determined using the curve fitting procedure (red dots), overlaying the ocean bathymetry from the ETOPO01 dataset (shaded contours); and (c) the time-mean number of fronts at each longitude. The boxes in (a) and (b) indicate the zoomed regions of Fig. 5.

vorticity structure is homogenized near the surface and the PV gradients are weak.

Using the skew normal fits we are able to determine, at every the longitude in the domain, the number of fronts $n$, their mean latitude $\bar{\phi}$, and their meandering standard deviation $\sigma$. The time-mean positions of the fronts are shown in Fig. 4b and are in agreement with previous studies such as Graham et al. (2012). The number of distinct peaks detected is shown in Fig. 4c, where it is clear that the number of fronts is highly variable, with as many as 15 peaks to as few as a one. Splitting behavior (where the number of fronts increases) occurs primarily downstream of large topographic features such as the Kerguelen Plateau (labeled in Fig. 4), while the inverse phenomena of merging (the number of fronts decreases downstream) occur primarily in regions where the flow is steered or constricted by topography. Note that at approximately $50^{\circ} \mathrm{W}$, the number of fronts reaches its global maxima due, in part, to the splitting and northward deviation of the SAF along the coast of South America, previously identified by Sokolov and Rintoul (2009a).

To demonstrate the variation of the frontal structure throughout the Southern Ocean, Fig. 5a shows zoomedview occurrence maps in the boxes indicated in Fig. 4, while Fig. $5 \mathrm{~b}$ shows the transects of the occurrence maps and their associated skew normal fits along the dashed lines in Fig. 5a. Box i, a region near the zonally oriented
Southeast Indian Ridge, shows a situation with two strong, persistent fronts (at approximately $47^{\circ}$ and $52^{\circ} \mathrm{S}$ ) and two less persistent fronts to the south (approximately $55^{\circ}$ and $60^{\circ} \mathrm{S}$ ), each with clearly identifiable, isolated maxima in the frontal occurrence transect [Fig. 5a(i)]. Along the chosen transect, it is clear that the fitting method identifies the four fronts and is able to reproduce the amplitudes and standard deviations of the transect of the occurrence map (i.e., the persistence and meandering of fronts).

The region in box ii, south of New Zealand and the Campbell Plateau, has more complex bathymetry than that of box $\mathrm{i}$ and the frontal structure is itself more complicated. In this region, the fitting procedure identifies six fronts. However, on closer inspection, the southern region of high frontal frequency (centered near $\sim 64^{\circ} \mathrm{S}$ ) as well as the front that follows the edge of the Campbell Plateau (at $\sim 53^{\circ} \mathrm{S}$ ) [Fig. 5a(ii)] are each represented by two overlapping skew normal functions: one that captures the dominant peak and broad shape of the that cluster and another that produces a secondary peak in frontal frequency $\left(\sim 52^{\circ} \mathrm{S}\right.$ and $\left.\sim 57^{\circ} \mathrm{S}\right)$ [Fig. 5b(ii)].

The frontal structure in box iii [Fig. 5a(iii)], in the eastern South Pacific, a region of generally flat bottom topography, differs from that of boxes i and ii. It is illustrative to compare the occurrence map in this region, which shows a broad area of elevated frontal occurrence frequency, with the snapshots in Fig. 1, where numerous 


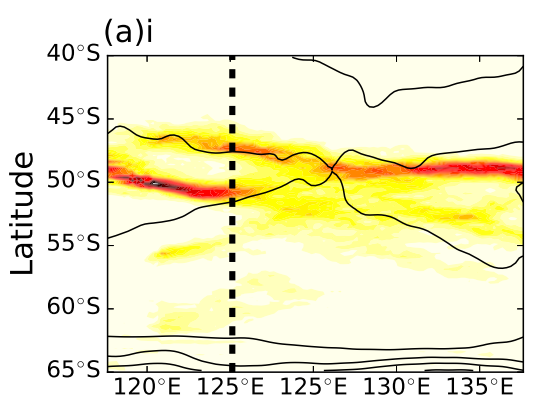

(a)ii
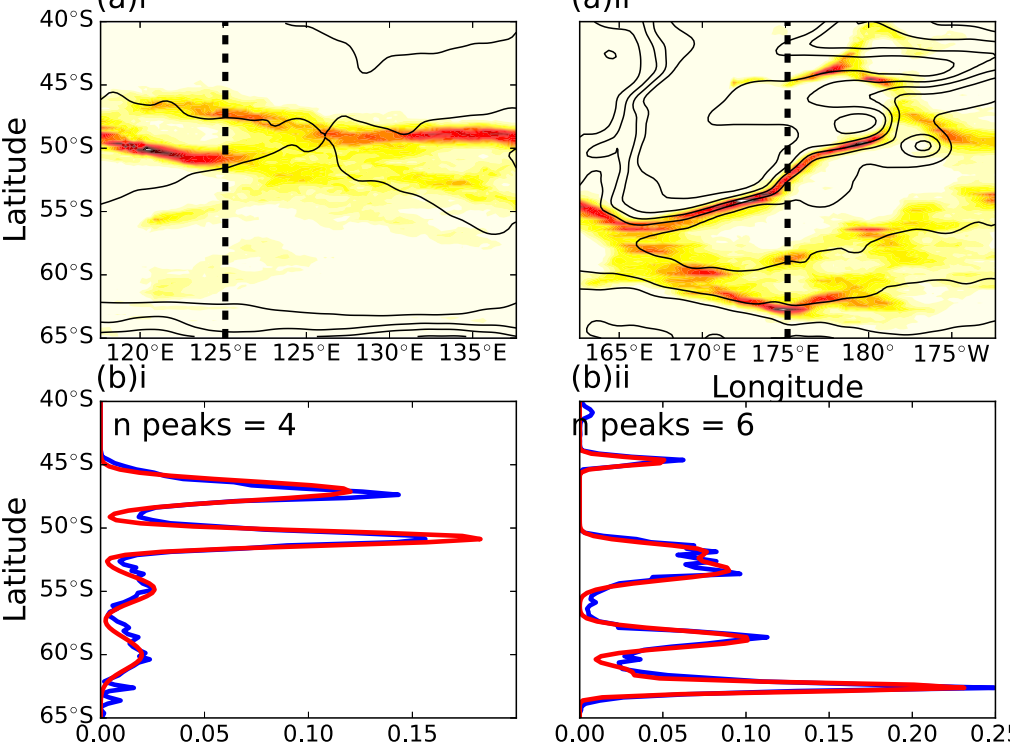

(a)iii

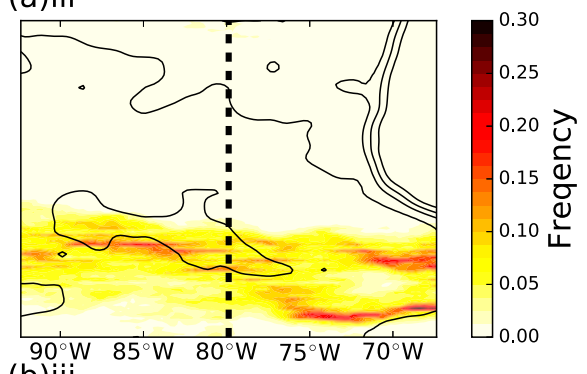

(b)iii

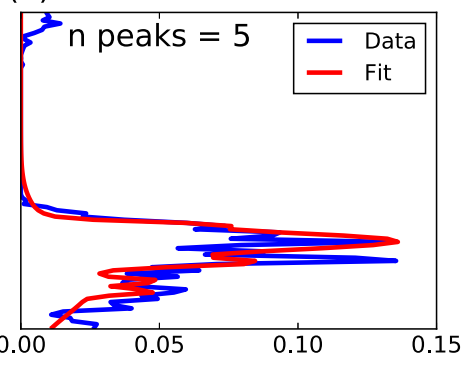

FIG. 5. Local variations in the frontal structure. [a(i)-a(iii)] Zoomed view of the frontal frequency of occurrence maps within the labeled boxes of Fig. 4 (note that the linear color scale) with the bathymetric contours [black solid lines: contour interval (CI) of $1000 \mathrm{~m}$ ] and $[\mathrm{b}(\mathrm{i})-\mathrm{b}(\mathrm{iii})]$ meridional transects of the frontal frequency of occurrence along the transects indicated by the dotted lines in upper panels (blue) and the associated skew normal curve fit (red).

braided fronts are evident. Further inspection reveals that the fronts here are ephemeral and closely packed together. The lack of persistence of these fronts and their close proximity acts to smear out the occurrence maps over a swath of latitudes. The transect through this region [Fig. 5b(iii)] indicates a region of high frontal recurrence spread over a range of latitudes, with two dominant peaks separated by less than $2^{\circ}$ of latitude as well as numerous subdominant peaks. The occurrence map is noisy in this region, and the fitting method, while able to effectively identify the locations of the two dominant peaks, does not capture all the subdominant peaks, instead representing them with a large enough standard deviation to encompass their regions of enhanced frontal occurrence frequency.

\section{b. Rearrangement of frontal structure near topography}

As noted above, fronts undergo splitting behavior downstream of large bathymetric features. Thompson et al. (2010) and Thompson and Sallée (2012) found a rearrangement of the underlying potential vorticity $(\mathrm{PV})$ structure downstream of bathymetric features by analyzing the PV or ADT using running PDFs. To understand how this rearrangement of the ADT structure is related to the structure of the fronts, we now recalculate the frontal occurrence map of Fig. 4a (ADT-longitude coordinates; shown in Fig. 6). Since fronts are expected, at least locally, to follow contours of sea surface height, regions of high frontal occurrence that cross or change streamlines indicate a reorganization of the frontal structure.

Persistent frontal activity does not necessarily follow ADT contours. In fact, many locations show a slow drift or spreading of the high frontal occurrence regions across ADT contours, as shown in Fig. 6. For example, two persistent fronts are present near the Pacific-Antarctic Rise (longitudes $160^{\circ}$ to $120^{\circ} \mathrm{W}$ ) that are strongly steered from north to south by the underlying bathymetry (which can be seen in Figs. 4a,b). In this region, in longitudeADT space, the fronts drift from approximately -0.1 to -1.0 dyn $\mathrm{m}$ over about $40^{\circ}$ of longitude - an approximate distance of $4000 \mathrm{~km}$ at this latitude-a decrease in dynamic height of $0.25 \mathrm{dyn} \mathrm{m}$ in $1000 \mathrm{~km}$. Additionally, the high frontal occurrence region spreads across the ADT, with elevated regions of frontal occurrence (greater than 0.1) being distributed between -1.0 and $-0.5 \mathrm{dyn} \mathrm{m}$ at $150^{\circ} \mathrm{W}$, whereas upstream of this feature, the fronts are limited to a more restricted set of ADT values (between 0 and 0.2 dyn $m$ at $185^{\circ}$ ). While highly persistent fronts (such as those found in regions of strong topographic steering) are generally constrained to a narrow range of latitudes, in longitude-ADT space the regions of high frontal occurrence frequencies can be present over a broad range of ADT.

We find that the spreading of the elevated frontal occurrence values across ADT contours occurs mainly within 


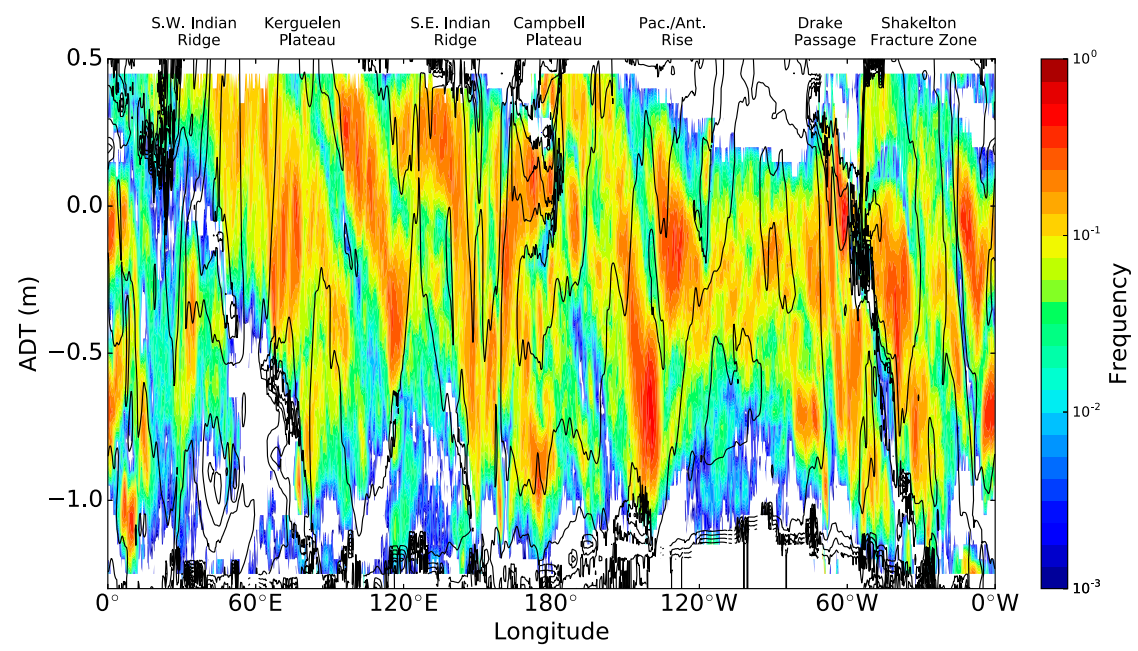

FIG. 6. The Southern Ocean frontal structure in ADT space; the frontal frequency of occurrence map (as in Fig. 4a) in longitude-ADT space. Solid black lines indicate bathymetric contours $(\mathrm{CI}=1000 \mathrm{~m})$. Large bathymetric features are labeled.

regions of frontal splitting. For example, downstream of the Campbell Plateau (box ii in Fig. 4), Fig. 6 shows a broadening of the elevated frontal occurrence values near $170^{\circ} \mathrm{E}$ from a narrow range farther upstream $\left(\sim 150^{\circ} \mathrm{E}\right)$. At the same location, Fig. $4 \mathrm{c}$ shows an increase from 2 stable fronts at $\sim 150^{\circ} \mathrm{E}$ to $8-10$ stable fronts at $\sim 170^{\circ} \mathrm{E}$.

To conclude this section, we note a remarkable similarity with Fig. 2a of Thompson and Sallée (2012; although the color scale is inverted), who analyzed the ADT using running PDFs to infer changes in the frontal structure and its underlying PV. The similarity between our results and those of Thompson and Sallée (2012) provides further confidence in our assertion that the splitting and merging of fronts is the manifestation of the reorganization of the PV structure that occurs downstream of large bathymetric features.

\section{c. Connection with fronts defined by contours of sea surface height}

We now compare the fronts detected by the WHOSE method with those defined by altimetrically derived dynamic height contours (Sokolov and Rintoul 2007). To proceed, we determine the value of the MDT from the Rio et al. (2014) dataset at each of the time-mean frontal locations in Fig. 4b. The normalized histogram of the MDT at the mean frontal locations, computed with an MDT bin spacing of 0.07 dyn $\mathrm{m}$, is shown in Fig. 7 a. Peaks in the histogram (dashed lines in Fig. 7a) are used to define a MDT value with which we can identify a front.

Four distinct peaks in the MDT histogram are identified. Based on comparisons with Sokolov and Rintoul (2007), we label the detected fronts the SAF and PF, both of which have a northern and a southern branch (denoted SAF-N and SAF-S in the case of the Subantarctic Fronts and PF-N and PF-S for the Polar Fronts). The values of the MDT used to define the fronts are listed in Table 1, along with comparable values from other studies. ${ }^{1}$ From a time-mean perspective, the selected MDT contours (solid lines in Fig. 7b) approximate well the time-mean location of the WHOSE fronts over the 21-yr period covered by the altimetry. Note that the SAACF is not analyzed in this study.

It is clear in Fig. $7 \mathrm{~b}$ that not all of the detected frontal positions are on one of the three MDT contours. To associate the time-mean front locations with one of the four traditional fronts defined here, we note that each of the peaks in the histogram is separated by a local minima (black star in Fig. 7a). Following Azzalini and Torelli (2007), we use the minima of the histogram to bound the time-mean front locations as belonging to one of the SAF-N, SAF-S, PF-N, or PF-S. Consider the PF-N, centered in MDT space on the peak of the histogram at -0.40 dyn $m$. These maxima are bounded by minima at MDTs -0.23 and -0.65 dyn $m$. All frontal locations falling in MDT space between these values are labeled as belonging to the PF-N. The classified time-mean frontal locations are shown in Fig. 7 as open circles, colored to indicate their classification.

\footnotetext{
${ }^{1}$ Note that there is no clearly defined definition of the SAF and the PF, and hence the naming convention differs between studies. For example, Volkov and Zlotnicki (2012) and Langlais et al. (2011) define the SAF-S at -0.4 dyn $\mathrm{m}$, where we have defined the PF-N, and Langlais et al. (2011) defines the PF-S at -0.68 dyn m, where here the MDT value is associated with the PF-N.
} 

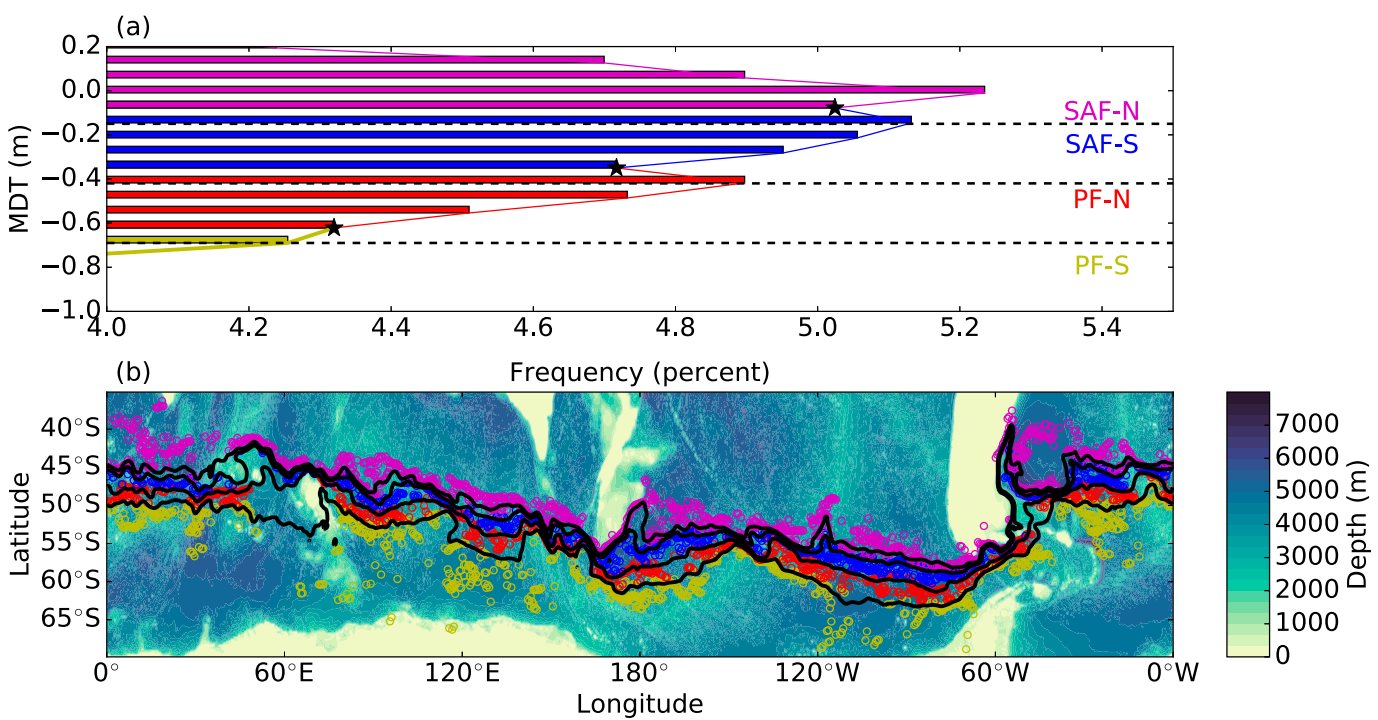

FIG. 7. The relationship of the time-mean frontal positions and the MDT contours. (a) The histogram of the MDT found at each time-mean front location (bin width of $0.07 \mathrm{dyn} \mathrm{m}$ ). The coloring of the curve indicates the region in MDT space associated with each named front, while the stars indicate the change from one frontal regime to another. (b) The time-mean locations of the fronts from Fig. 4b (colored open circles) with the position of those same fronts defined using contours of MDT (solid lines) overlying the ocean bathymetry. The fronts are color coded from north to south as SAF-N (magenta), SAF-S (blue), PF-N (red), and PF-S (yellow).

By classifying the small-scale WHOSE fronts in this manner we are able to identify regions associated with a particular hydrographic front, as opposed to a single location. For example, we can see in Fig. 7b that the region associated with the SAF-S, PF-N, and PF-S generally extends to the south of the contour used to define them and generally fill the area between the bounding contours. As such, the area covered by each of the identified fronts is not constant but varies throughout the domain.

By classifying the WHOSE fronts in this manner, ephemeral, splitting, or meandering fronts that do not fall on a predetermined contour of sea surface height may still be grouped together and analyzed. We will make extensive use of this classification scheme in the following sections in order to study the Southern Ocean front's temporal and spatial variability.

\section{d. Spatial variations of frontal meandering}

Recall that at each longitude, each fitted skew normal function has an associated standard deviation $\sigma$ defined in Eq. (3). This standard deviation is plotted in Fig. 8 for each labeled front (averaged across all points that belong to a particular front), together with the timeaveraged eddy kinetic energy (EKE), defined as

$$
\mathrm{EKE}=\frac{1}{2} \overline{\mathbf{u}^{\prime} \cdot \mathbf{u}^{\prime}},
$$

where $\mathbf{u}^{\prime}=\left(u^{\prime}, v^{\prime}\right)$ is the horizontal surface perturbation velocity obtained from the AVISO SLA data. The quantities are determined at each of the time-mean frontal locations, determined from the altimetric surface velocity anomalies.

All four fronts show a mean standard deviation of about $0.5^{\circ}$ across all longitudes. Although there are variations from the mean value at various locations throughout the Southern Ocean, notably a large increase in the standard deviation upstream of the Kerguelen Plateau at around $60^{\circ} \mathrm{E}$ where the ACC is influenced by the Aghulas Current and a moderate decrease in regions where the flow is strongly steered by bathymetry, such as through Drake Passage, at the Pacific Antarctic Rise, and the Campbell Plateau. However, over the entire circumpolar circuit, there is little variation in the standard deviation. There is also no significant correlation between the EKE and standard deviation. In contrast, it is clear from Fig. $4 c$ that the number of fronts varies substantially throughout the

TABLE 1. ADT values used to define the fronts in this and two others studies that make use of comparable data.

\begin{tabular}{lcccc}
\hline \hline & \multicolumn{4}{c}{ ADT (dyn m) } \\
\cline { 2 - 5 } Front & $\begin{array}{c}\text { This } \\
\text { study }\end{array}$ & $\begin{array}{c}\text { Langlais et al. } \\
(2011)\end{array}$ & $\begin{array}{c}\text { Volkov and } \\
\text { Zlotnicki (2012) }\end{array}$ & $\begin{array}{c}\text { Kim and } \\
\text { Orsi (2014) }\end{array}$ \\
\hline SAF-N & -0.01 & - & - & -0.03 \\
SAF-S & -0.15 & -0.16 & -0.2 & - \\
PF-N & -0.42 & -0.40 & -0.4 & - \\
PF-S & -0.69 & -0.68 & -1.0 & -0.61 \\
\hline
\end{tabular}




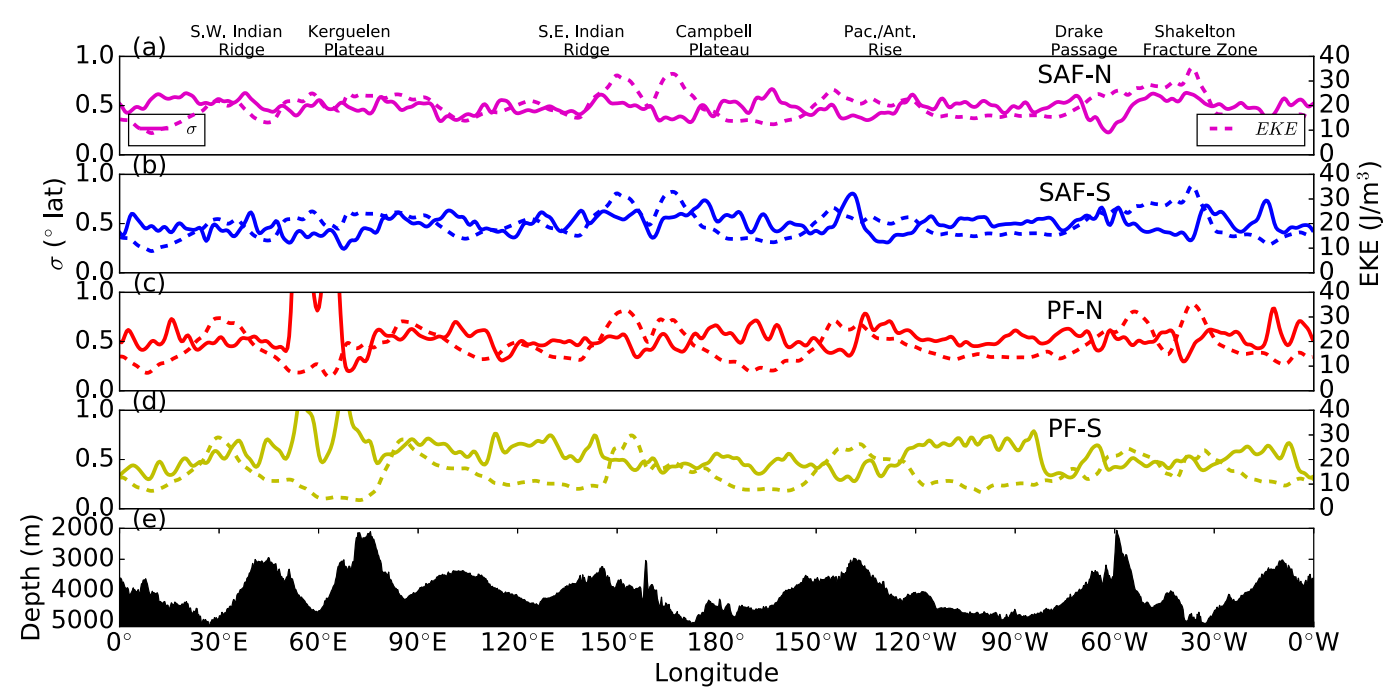

FIG. 8. The average standard deviation $\sigma$ determined by the fitted skew normal distributions to the frontal frequency of occurrence maps (solid) and the eddy kinetic energy (dashed) for the (a) SAF-N, (b) SAF-S, (c) PF-N, and (d) PF-S. (e) The bathymetry averaged across the ACC is shown for reference.

Southern Ocean and that these variations are spatially coherent.

The fact that the standard deviation remains roughly constant throughout the Southern Ocean, while the number of fronts varies substantially provides some basis to claim that the dominant manifestation of spatial variability in the Southern Ocean is not a change in the capacity of fronts to meander but is instead the splitting of the fronts into subfronts. These results are consistent with the analysis of the PV in a high-resolution ocean model by Thompson et al. (2010), who show rearrangement of the PV structure consistent with frontal splitting in the regions corresponding to boxes ii and iii in Fig. 5.

It should be noted that Shao et al. (2015) have performed a similar calculation (see their Fig. 6) that is in agreement with the data presented here for the SAF but not completely in agreement with the their calculations for the PF, which shows peaks in variability downstream of the Kerguelen Plateau, Campbell Plateau, in the east Pacific, and through Drake Passage. The reasons for this disagreement are unclear. We note that the methodology used by Shao et al. (2015) sets the number of fronts a priori and thus is unable to capture the influence that the splitting/merging of fronts might have on the estimates of frontal variability, and it is possible that, for example, their skewness criteria will at times identify a branch of the SAF and at times identify a branch of the PF, which would manifest as enhanced variability in these regions. Shao et al. (2015) do, however, discuss several plausible dynamical mechanisms that could give rise to enhanced variability in jet locations downstream of large topographic features. Despite these disagreements, we emphasize that outside of the identified regions, the fronts detected by Shao et al. (2015) show little change in their capacity to meander.

\section{Temporal variability of Southern Ocean fronts}

We now seek to determine the long-term changes in frontal location and ascertain if the frontal structure is sensitive to changes in atmospheric forcing.

\section{a. Long-term trends in frontal positions}

Using our methodology we now estimate the trends in frontal locations to determine where, if any, changes in the positions of these fronts have occurred over the satellite period. To accomplish this, we form annual occurrence maps and fit the skew normal function, yielding annual-mean frontal locations for each year from 1993 to 2014. We then associated each frontal location with one of the SAF-N, SAF-S, PF-N, or PF-S using the MDT values described in section 3 and find the mean latitude for each of the labeled fronts at every longitude and for every year in the database. Trends in the annual mean position of the fronts are then obtained at each longitude using standard linear regression and are shown in Fig. 9, along with regions where the trends are statistically significant at the $90 \%$ level (i.e., $p<0.1$ ).

We find do not find any substantial trends in the locations of the fronts, although there is some suggestion of a trend of between $-0.1^{\circ}$ and $-0.2^{\circ} \mathrm{yr}^{-1}$ in the $\mathrm{PF}$ at approximately $60^{\circ} \mathrm{E}$. This region was also found by 


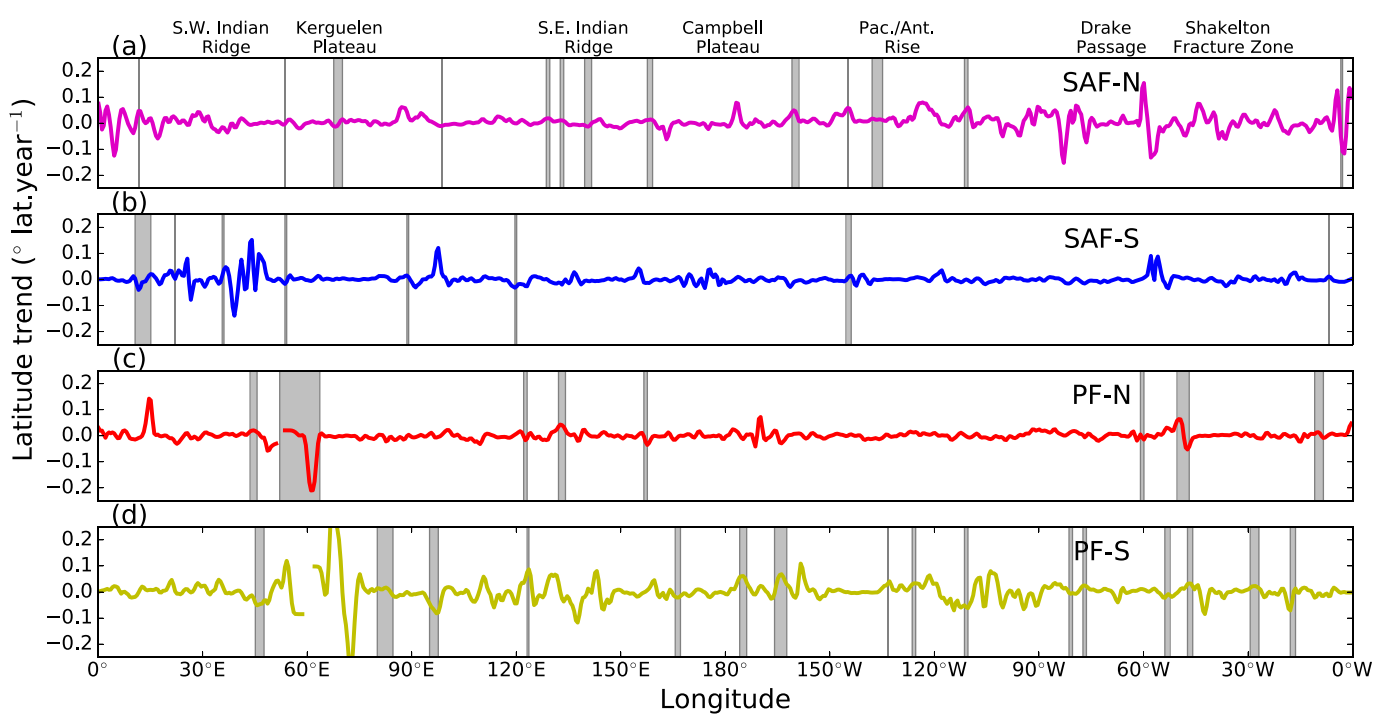

FIG. 9. Trends in the mean latitudinal position of the (a) SAF-N, (b) SAF-S, (c) PF-N, and (d) PF-S. Gray shading indicates regions where the trend is statistically significant at the $90 \%$ level $(p<0.1)$.

Kim and Orsi (2014) to host reasonably large (approximately $0.1^{\circ} \mathrm{yr}^{-1}$ ) and statistically significant shifts in the PF position. However, despite our $p$ value of less than 0.1 , the lack of spatial coherence in the trend as well as the lack of any statistically significant trends in the neighboring frontal branches means that we are unable to place a large degree of confidence in this apparent southward trend being the result of any real physical shift in the front's location. To illustrate this point, Fig. 10 shows the time-mean positions of the fronts for the period 1993-97 (crosses) and 2009-14 (triangles). Although Fig. 9 does show certain limited regions where the calculated trend in the frontal location is both nonzero and statistically significant at the $90 \%$ level, Fig. 10 shows a lack of clear variation in frontal locations, even in those few regions with significant frontal trends.

The lack of trends found in our analysis is contrary to many studies that employ the contour-type method (Sallée et al. 2008; Sokolov and Rintoul 2009b; Kim and Orsi 2014) that finds localized southward shifts of the fronts, between $0.5^{\circ}$ and $2^{\circ}$, depending on the details of the methodology, the geographical region, and the front under consideration. However, our results are consistent with the analyses of Graham et al. (2012), Gille (2014), and Shao et al. (2015), who find little or no long-term trends in the fronts.

\section{b. Response of fronts to ENSO and SAM}

Although we have not found any appreciable longterm variability, we have not ruled out forced interannual variability associated the SAM or ENSO. As in Kim and Orsi (2014), we designate a high (low) SAM or ENSO event to occur when the value of the index was greater (less) than one standard deviation from the mean. We then form four ensemble-mean frontal occurrence maps: high SAM, low SAM, high ENSO (i.e., El Niño), and low ENSO (La Niña). The differences between the ensemble occurrence maps calculated during El Niño and La Niña periods is shown in Fig. 11a, while the difference between the occurrence maps obtained during strongly positive and strongly negative SAM periods is shown in Fig. 11b. Statistical significance is estimated using a bootstrapping method, with a 1500 samples drawn randomly (with replacement) at each grid point on the domain, from the samples that occur during negative SAM or ENSO periods. The resampling procedure is repeated 1000 times to estimate the distribution of the difference between positive and negative $\mathrm{SAM} / \mathrm{ENSO}$ at each grid point, and a $p$ value is determined from the empirical CDF.

For both climate modes, we find local changes in the frontal occurrence frequency of as much as $15 \%$. There is also some indication of coherent frontal shifts in certain regions. For example, downstream of the Kerguelen Plateau (at approximately $110^{\circ} \mathrm{E}$ ), south of Australia $\left(130^{\circ} \mathrm{E}\right)$, and in Drake Passage $\left(60^{\circ} \mathrm{W}\right)$, there is evidence of a frontal shift to the south during La Niña periods. Similarly, in the eastern Pacific, near the PacificAntarctic Rise $\left(140^{\circ} \mathrm{W}\right)$, there is evidence of frontal shifts to the south during negative SAM periods. These shifts are, however, small: less than $1.0^{\circ}$ of latitude and generally less than $0.5^{\circ}$, which is approaching the effective resolution of the gridded dataset. The largest movements of the fronts appear to be along the northern 


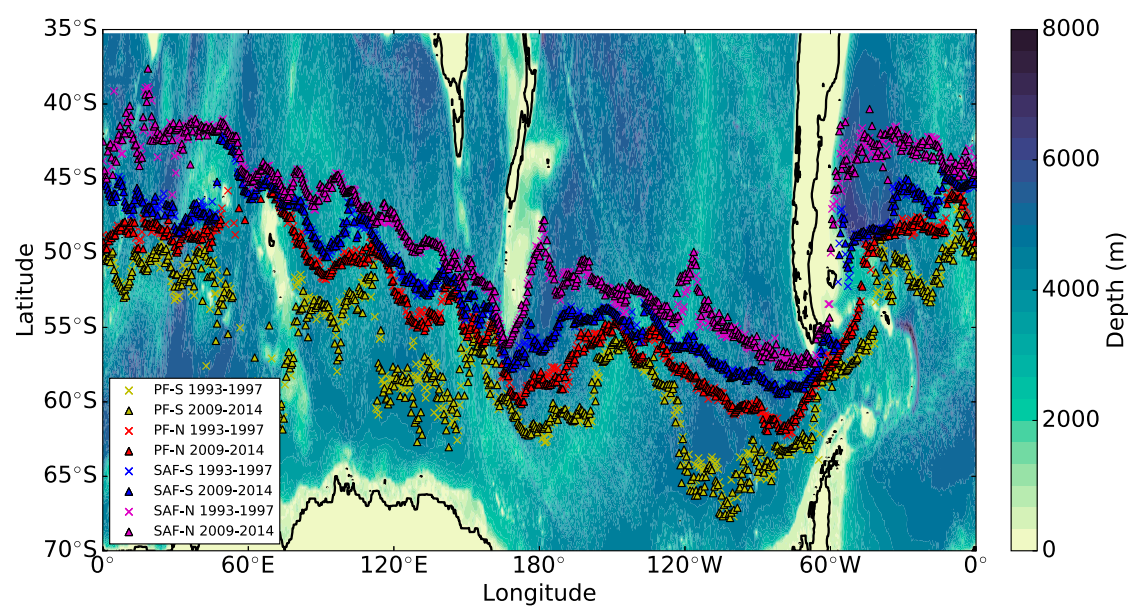

FIG. 10. The mean positions of the fronts during the period 1993-97 (crosses) and the period 2009-14 (triangles). The fronts are color coded from north to south as SAF-N (magenta), SAF-S (blue), PF-N (red), and PF-S (yellow).

boundary of the ACC, although these shifts are neither spatially coherent nor large in magnitude. Any shifts in frontal position detected here are generally limited to less than $1.0^{\circ}$ of latitude and have a coherent spatial extent of no more than $10^{\circ}$ of longitude. We also find no changes in the frontal occurrence maps driven by the ENSO significant at the $90 \%$ level and only a few regions that show statistically significant frontal shifts with changes in the SAM. In fact, statistical significance is often lacking even in regions with relatively coherent changes in occurrence frequency. However, it seems likely that the shift in front position to the south near the
Pacific-Antarctic Rise during negative SAM events is both spatially coherent and statistically significant.

Essentially, we have not found significant sensitivity of fronts to the two leading climate modes over the Southern Ocean, although there is the suggestion of limited variability in a few select regions. As with the analysis of long-term trends, our results are at odds with a number of studies employing contour methods who show localized sensitivity to ENSO or SAM (Sallée et al. 2008; Kim and Orsi 2014) yet in broad agreement with other who find limited or no response to changes in atmospheric forcing (Graham et al. 2012; Shao et al. 2015),

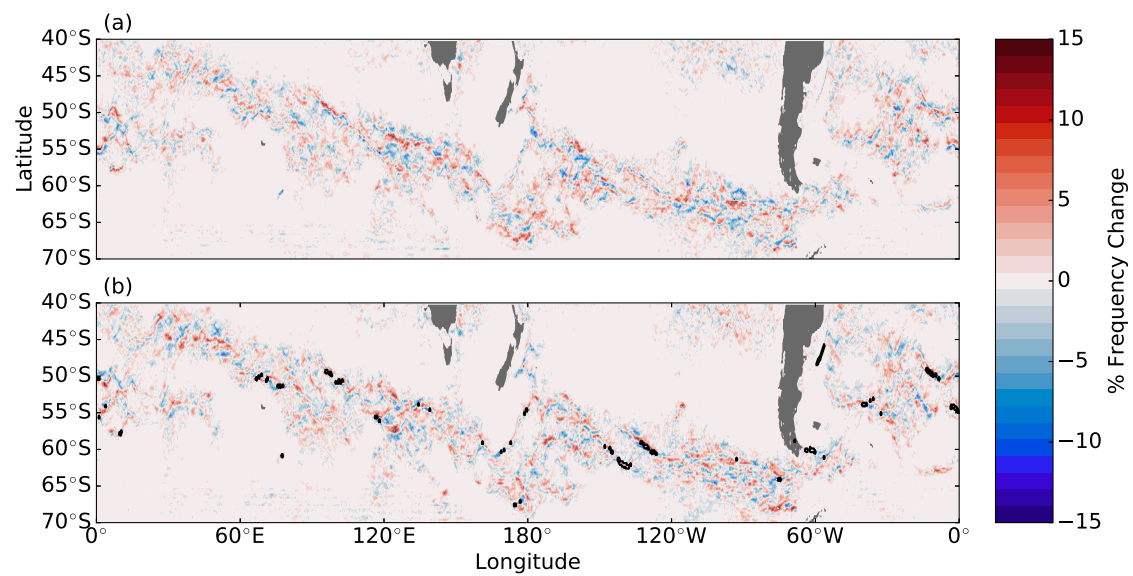

FIG. 11. The influence of the SAM and ENSO on frontal positions. (a) The occurrence maps anomaly calculated by subtracting the occurrence map determined during La Niña periods from El Niño periods. (b) As in (a), but subtracting the negative SAM occurrence maps from the positive SAM occurrence maps. Warm colors indicate that a front is more likely to be present at that location during positive events, while cool colors indicate a tendency for a front to be present during negative events. The black solid contour shows regions significant at the $90 \%$ level $(p<0.1)$. 
although it is notable that the later study does find statistically significant correlation between frontal position and the SAM in a limited number of geographic regions, such as the south of Australia between $120^{\circ} \mathrm{E}-180^{\circ}$ and the east Pacific near $60^{\circ} \mathrm{W}$. However, the correlation of the frontal positions with changing SAM found by Shao et al. (2015) are noisy, and the authors warn against placing too much confidence in the statistical significance of the correlations. Unlike Shao et al. (2015), and consistent with Graham et al. (2012), we find no statistically significant frontal displacements in the south of Australia with changing SAM.

\section{Discussion and conclusions}

In this paper, we have applied the WHOSE method, described in Chapman (2014), to $21 \mathrm{yr}$ of gridded sea surface height altimetry in order to investigate the spatial and temporal variability of mesoscale fronts in the Southern Ocean. We have attempted to tease out concrete conclusions from a complex dataset by forming occurrence maps of the frontal occurrence frequency and then approximating these maps by fitting a superposition of skew normal curves. This approach allows us to quasi objectively determine the number of fronts at each latitude and their time-mean position. With these data, we are able to investigate in detail their spatial and temporal variability of the frontal structure.

The principle result of this study is the identification of marked spatial variation in the frontal structure throughout the Southern Ocean latitudes. We find that downstream of large bathymetric features and over regions of relatively flat bottom topography, the frontal structure responds by splitting into a number of subfronts, whereas over large bathymetry, the fronts constrained are merged together. This splitting/merging variability is distinct from meandering, where a front changes its location yet remains coherent. In several regions within the Southern Ocean, splitting and merging behavior is observed, while, with the exception of a single location near the Aghulas Current, fronts do not show marked changes in coherent meandering.

The distinction between splitting and meandering is important, as splitting represents a reorganization of the frontal structure, which in turn indicates a reorganization of the underlying potential vorticity structure in a way that a simple meandering of a front does not. The analysis of the occurrence maps in ADT space, shown in Fig. 6, which is consistent with earlier studies by Thompson et al. (2010) and Thompson and Sallée (2012), shows regions of high frontal frequency broadening and crossing SSH contours, indicative of fronts changing their surface expression due to an underlying reorganization of the potential vorticity structure.

As discussed by Thompson (2010) in the context of a series of idealized numerical experiments, the control exerted by the topography over the frontal structure may have important implications for the meridional transport of tracers. It has been well established that cross-frontal fluxes are enhanced downstream of bathymetric features (Thompson and Sallée 2012; Dufour et al. 2015). However, our analysis has indicated that fronts, along with their associated mixing barriers, split into a series subfronts downstream of large bathymetry. Detailed eddy diffusivity calculations undertaken by Shuckburgh et al. (2009) in the Pacific sector of the Southern Ocean have shown reorganization of the diffusivity in certain regions from broad regions of high diffusivity to regions of alternating high and low diffusivity that is reminiscent of the splitting of fronts demonstrated in this paper. As such, transport barriers are still present in these mixing hotspot regions, although they are likely weaker than the mixing barriers associated with strong, persistent fronts (Ferrari and Nikurashin 2010). As such, tracers may not cross the ACC region in a single region but may instead shift from one latitude to another within the ACC before being advected farther downstream.

Additionally, it has been shown by Jayne and Marotzke (2002) that a meandering yet coherent jet does not induce any net tracer transport. However, if the primary spatial variability exhibited by Southern Ocean fronts is splitting and merging, instead of a modulation of the meandering, then it is likely that the dynamics of eddy transport are more complicated than may have been assumed. More work is required to untangle the dynamics of the interaction between eddy transport and fronts in the regions downstream of bathymetry.

The second key results arising from this work is that the fronts determined by our methodology show no significant trends in their position and only limited, and localized, sensitivity to the changes in atmospheric forcing associated with the southern annual mode or El Niño-Southern Oscillation. The lack of temporal variability is consistent with the results of previous studies (Graham et al. 2012; Gille 2014; Shao et al. 2015). There are, however, several studies employing contour methods that have shown trends in the position of the fronts in particular locations (Sokolov and Rintoul 2009b; Kim and Orsi 2014). In contrast our results do not indicate coherent trends in any region, with the possible exception of in the southeast Indian sector.

By determining the mean dynamic topography at each frontal location found by the WHOSE method, we are able to associate each frontal filament with a branch of 


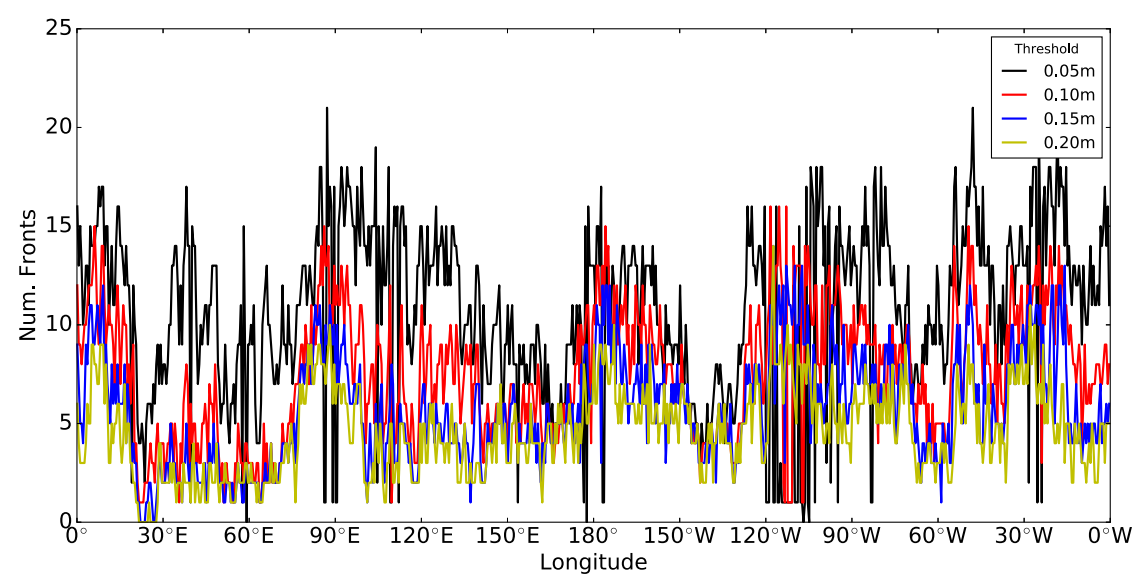

FIG. C1. The sensitivity of number of Southern Ocean fronts with changing gradient threshold. Values of the gradient threshold employed are 0.05 (black), 0.10 (red, value used in the main text), 0.15 (blue), and $0.20 \mathrm{~m}$ (yellow) per $100 \mathrm{~km}$.

either the Subantarctic Front or the Polar Front. In this way, we can link the traditional three front pictures of the Southern Ocean with the filamentary frontal structure revealed by the WHOSE method. In lieu of identifying a single labeled front, we are now able to identify frontal regions. It was shown in section 3 that contour methods do accurately represent the time-mean locations and, for the most part, orientations of the WHOSE fronts. However, as shown in Fig. 6b, and echoing the work of Graham et al. (2012), regions of high frontal occurrence are not always clustered around a restricted set of sea surface height values. Contour methods still remain invaluable due to their simplicity of application, relationship with traditional hydrographic front, and usefulness in defining a circumpolar coordinate system for cross-frontal flux calculations (Langlais et al. 2011).

The work presented in this paper presents a new interpretation of the complexity of the frontal structure in the Southern Ocean that, unfortunately, belies simple interpretation. Future work will focus on investigating the implications that the continual reorganization of the frontal structure has for the large-scale circulation in the Southern Ocean and the dynamics of splitting and merging as well as more rigorously and precisely defining the frontal regimes present.

Acknowledgments. This research was funded by a National Science Foundation Division of Ocean Sciences Postdoctoral Fellowship 1521508. The author thanks Robert Graham, Sabine Arnault, Andrew Shao, and an anonymous reviewer for comments on an earlier draft of this manuscript and Jean-Baptiste Sallée for useful discussions and encouragement.

\section{APPENDIX A}

\section{Software Availability}

Implementations of the WHOSE method and the curve fitting procedure, written in the open-source Python programming language, is available as opensource software (under an MIT license) from the author's GitHub repository (https://github.com/ChrisC28).

\section{APPENDIX B}

\section{Availability of WHOSE Front Locations}

The frontal locations determined by the WHOSE method have been made freely available for download (available online at http://dx.doi.org/10.5061/dryad. q9k8r). The data are stored in NetCDF files and consist of daily output between latitudes $70^{\circ}$ and $35^{\circ} \mathrm{S}$, with a grid spacing of $14^{\circ}$, identical to that of the AVISO data from which it is generated. The data are binary; for each point in the domain, a TRUE value indicates the presence of a front, while a FALSE indicates that no front was found at that location or time.

\section{APPENDIX C}

\section{Sensitivity of the Methodology to Parameter Choices}

The WHOSE method is a parametric method; that is, certain parameters must be chosen a priori by the user. For the WHOSE method, these parameters are the confidence parameter $\alpha$, used for the Kurtosis thresholding in the WHOSE methodology [step 2 in section 2c; 
also see Chapman (2014)], and the gradient threshold for the eventual detection of the fronts.

We have tested the sensitivity of the number of fronts detected of both these parameters. As the WHOSE method as well as the fitting of skew normal functions is computationally intensive, we have limited the sensitivity analysis to a single year: 2010 . We have found that provided $\alpha$ is greater than 0.8 , the results are almost insensitive to the value of the confidence parameter. The number of fronts is, however, sensitive to the gradient threshold used. Recall that the threshold used in this study was $0.1 \mathrm{~m}$ per $100 \mathrm{~km}$ (red). We have additionally tested values of 0.05 (black), 0.15 (blue), and $0.2 \mathrm{~m}$ (yellow) per $100 \mathrm{~km}$. The number of fronts obtained for each value is shown in Fig. C1.

Although the number of fronts is sensitive to the value of the gradient threshold, the broad-scale pattern of splitting and merging remains intact, with the possible exception of in the South Atlantic (between $30^{\circ}$ and $60^{\circ} \mathrm{E}$ ) for the gradient threshold of $0.05 \mathrm{~m}$ per $100 \mathrm{~km}$. We note that there is little variation in the number of fronts over the Southern Ocean between the gradient thresholds of $0.1,0.15$, and $0.2 \mathrm{~m}$ per $100 \mathrm{~km}$.

\section{REFERENCES}

Akaike, H., 1974: A new look at the statistical model identification. IEEE Trans. Autom. Control, 19, 716-723, doi:10.1109/ TAC.1974.1100705.

Azzalini, A., and A. Capitanio, 1999: Statistical applications of the multivariate skew normal distribution. J. Roy. Stat. Soc., 61B, 579-602, doi:10.1111/1467-9868.00194.

_ , and N. Torelli, 2007: Clustering via nonparametric density estimation. Stat. Comput., 17, 71-80, doi:10.1007/s11222-006-9010-y.

Belkin, I. M., and A. L. Gordon, 1996: Southern Ocean fronts from the Greenwich meridian to Tasmania. J. Geophys. Res., 101, 3675-3696, doi:10.1029/95JC02750.

Billany, W., S. Swart, J. Hermes, and C. Reason, 2010: Variability of the Southern Ocean fronts at the Greenwich meridian. J. Mar. Syst., 82, 304-310, doi:10.1016/j.jmarsys.2010.06.005.

Böning, C. W., A. Dispert, M. Visbeck, S. Rintoul, and F. U. Schwarzkopf, 2008: The response of the Antarctic Circumpolar Current to recent climate change. Nat. Geosci., 1, 864869, doi:10.1038/ngeo362.

Burls, N. J., and C. J. C. Reason, 2006: Sea surface temperature fronts in the midlatitude South Atlantic revealed by using microwave satellite data. J. Geophys. Res., 111, C08001, doi:10.1029/2005JC003133.

Burnham, K. P., D. R. Anderson, and K. P. Huyvaert, 2011: AIC model selection and multimodel inference in behavioral ecology: Some background, observations, and comparisons. Behav Ecol. Sociobiol., 65, 23-35, doi:10.1007/s00265-010-1029-6.

Chapman, C. C., 2014: Southern Ocean jets and how to find them: Improving and comparing common jet detection methods. J. Geophys. Res. Oceans, 119, 4318-4339, doi:10.1002/2014JC009810.

- , and A. M. Hogg, 2013: Jet jumping: Low-frequency variability in the Southern Ocean. J. Phys. Oceanogr., 43, 9901003, doi:10.1175/JPO-D-12-0123.1.
- and R. Morrow, 2014: Variability of Southern Ocean jets near topography. J. Phys. Oceanogr., 44, 676-693, doi:10.1175/ JPO-D-13-0182.1.

— A. M. Hogg, A. E. Kiss, and S. R. Rintoul, 2015: The dynamics of Southern Ocean storm tracks. J. Phys. Oceanogr., 45, 884-903, doi:10.1175/JPO-D-14-0075.1.

CLS, 2013: MSS_CNES-CLS13 Mean Dynamic Topography. Aviso, accessed 12 January 2015. [Available online at http:// www.aviso.altimetry.fr/fr/donnees/produits/produitsauxiliaires/mdt.html.]

Deacon, G. E. R., 1937: The Hydrology of the Southern Ocean. Cambridge University Press, $124 \mathrm{pp}$.

Dong, S., J. Sprintall, and S. T. Gille, 2006: Location of the Antarctic polar front from AMSR-E satellite sea surface temperature measurements. J. Phys. Oceanogr., 36, 2075-2089, doi:10.1175/JPO2973.1.

Donoho, D. L., and J. M. Johnstone, 1995: De-noising by softthresholding. IEEE Trans. Inf. Theory, 41, 613-627, doi:10.1109/18.382009.

Dufour, C. O., and Coauthors, 2015: Role of mesoscale eddies in cross-frontal transport of heat and biogeochemical tracers in the Southern Ocean. J. Phys. Oceanogr., 45, 3057-3081, doi:10.1175/JPO-D-14-0240.1.

Ferrari, R., and M. Nikurashin, 2010: Suppression of eddy diffusivity across jets in the Southern Ocean. J. Phys. Oceanogr., 40, 1501-1519, doi:10.1175/2010JPO4278.1.

Foppert, A., K. A. Donohue, and D. R. Watts, 2016: The polar front in Drake Passage: A composite-mean stream-coordinate view. J. Geophys. Res. Oceans, 121, 1771-1788, doi:10.1002/ 2015 JC011333.

Freeman, N. M., N. S. Lovenduski, and P. R. Gent, 2016: Temporal variability in the Antarctic polar front (2002-2014). J. Geophys. Res. Oceans, 121, 7263-7276, doi:10.1002/ 2016JC012145.

Gille, S. T., 1994: Mean sea surface height of the Antarctic Circumpolar Current from Geosat data: Method and application. J. Geophys. Res., 99, 18255-18273, doi:10.1029/94JC01172. 2014: Meridional displacement of the Antarctic Circumpolar Current. Philos. Trans. Roy. Soc. London, A372, 20130273, doi:10.1098/rsta.2013.0273.

Graham, R. M., A. M. Boer, K. J. Heywood, M. R. Chapman, and D. P. Stevens, 2012: Southern Ocean fronts: Controlled by wind or topography? J. Geophys. Res., 117, C08018, doi:10.1029/2012JC007887.

Hallberg, R., and A. Gnanadesikan, 2006: The role of eddies in determining the structure and response of the wind-driven Southern Hemisphere overturning: Results from the Modeling Eddies in the Southern Ocean (MESO) project. J. Phys. Oceanogr., 36, 2232-2252, doi:10.1175/ JPO2980.1.

Hughes, C. W., 1996: The Antarctic Circumpolar Current as a waveguide for Rossby waves. J. Phys. Oceanogr., 26, 1375-1387, doi:10.1175/1520-0485(1996)026<1375:TACCAA > 2.0.CO;2. , and E. R. Ash, 2001: Eddy forcing of the mean flow in the Southern Ocean. J. Geophys. Res., 106, 2713-2722, doi:10.1029/2000JC900332.

, A. F. Thompson, and C. Wilson, 2010: Identification of jets and mixing barriers from sea level and vorticity measurements using simple statistics. Ocean Modell., 32, 44-57, doi:10.1016/ j.ocemod.2009.10.004.

Jayne, S. R., and J. Marotzke, 2002: The oceanic eddy heat transport. J. Phys. Oceanogr., 32, 3328-3345, doi:10.1175/ 1520-0485(2002)032<3328:TOEHT>2.0.CO;2. 
Kim, Y. S., and A. H. Orsi, 2014: On the variability of Antarctic Circumpolar Current fronts inferred from 1992-2011 altimetry. J. Phys. Oceanogr., 44, 3054-3071, doi:10.1175/JPO-D-13-0217.1.

Kostianoy, A. G., A. I. Ginzburg, S. A. Lebedev, M. Frankignoulle, and B. Delille, 2003: Fronts and mesoscale variability in the southern Indian Ocean as inferred from the TOPEX/Poseidon and ERS-2 altimetry data. Oceanology, 43, 632-642.

Langlais, C., S. Rintoul, and A. Schiller, 2011: Variability and mesoscale activity of the Southern Ocean fronts: Identification of a circumpolar coordinate system. Ocean Modell., 39, 79-96, doi:10.1016/j.ocemod.2011.04.010.

Marshall, G. J., 2003a: Trends in the southern annular mode from observations and reanalyses. J. Climate, 16, 4134-4143, doi:10.1175/1520-0442(2003)016<4134:TITSAM >2.0.CO;2.

- 2003b: Monthly southern annular mode indices, continuing from 1957 (updated monthly). British Antarctic Survey, accessed 22 April 2016. [Available online at http://www.nerc-bas. ac.uk/icd/gjma/sam.html.]

Meijers, A., 2014: The Southern Ocean in the coupled model intercomparison project phase 5. Philos. Trans. Roy. Soc. London, A372, 20130296, doi:10.1098/rsta.2013.0296.

_ E. Shuckburgh, N. Bruneau, J.-B. Sallee, T. Bracegirdle, and Z. Wang, 2012: Representation of the Antarctic Circumpolar Current in the CMIP5 climate models and future changes under warming scenarios. J. Geophys. Res., 117, C12008, doi:10.1029/2012JC008412.

Moore, J. K., M. R. Abbott, and J. G. Richman, 1999: Location and dynamics of the Antarctic polar front from satellite sea surface temperature data. J. Geophys. Res., 104, 3059-3073, doi:10.1029/1998JC900032.

Orsi, A. H., T. Whitworth, and W. D. Nowlin, 1995: On the meridional extent and fronts of the Antarctic Circumpolar Current. Deep-Sea Res. I, 42, 641-673, doi:10.1016/0967-0637(95)00021-W.

Pujol, M.-I., Y. Faugère, G. Taburet, S. Dupuy, C. Pelloquin, M. Ablain, and N. Picot, 2016: DUACS DT2014: The new multi-mission altimeter data set reprocessed over 20 years. Ocean Sci., 12, 1067-1090, doi:10.5194/os-12-1067-2016.

Ravier, P., and P.-O. Amblard, 1998: Combining an adapted wavelet analysis with fourth-order statistics for transient detection. Signal Process., 70, 115-128, doi:10.1016/ S0165-1684(98)00117-0.

Rintoul, S. R., and A. C. Naveira-Garabato, 2013: Dynamics of the Southern Ocean circulation. Ocean Circulation and Climate: $A$ 21st Century Perspective, G. Siedler et al., Eds., International Geophysics Series, Vol. 103, Academic Press, 471-492, doi:10.1016/B978-0-12-391851-2.00018-0.

Rio, M.-H., S. Mulet, and N. Picot, 2014: Beyond GOCE for the ocean circulation estimate: Synergetic use of altimetry, gravimetry, and in situ data provides new insight into geostrophic and Ekman currents. Geophys. Res. Lett., 41, 8918-8925, doi:10.1002/2014GL061773.

Sallée, J. B., K. Speer, and R. Morrow, 2008: Response of the Antarctic Circumpolar Current to atmospheric variability. J. Climate, 21, 3020-3039, doi:10.1175/2007JCLI1702.1.

Shao, A. E., S. T. Gille, S. Mecking, and L. Thompson, 2015: Properties of the subantarctic front and polar front from the skewness of sea level anomaly. J. Geophys. Res. Oceans, $\mathbf{1 2 0}$, 5179-5193, doi:10.1002/2015JC010723.
Shuckburgh, E., H. Jones, J. Marshall, and C. Hill, 2009: Understanding the regional variability of eddy diffusivity in the Pacific sector of the Southern Ocean. J. Phys. Oceanogr., 39, 2011-2023, doi:10.1175/2009JPO4115.1.

Smith, C. A., and P. D. Sardeshmukh, 2000a: The effect of ENSO on the intraseasonal variance of surface temperatures in winter. Int. J. Climatol., 20, 1543-1557, doi:10.1002/ 1097-0088(20001115)20:13<1543::AID-JOC579>3.0.CO;2-A. , and _ 2000b: Monthly bivariate ENSO time series, continuing from 1870 (updated monthly). NOAA/ESRL, accessed 8 April 2016. [Available online at https://www.esrl. noaa.gov/psd/people/cathy.smith/best/.]

Sokolov, S., and S. R. Rintoul, 2002: Structure of Southern Ocean fronts at $140^{\circ}$ E. J. Mar. Syst., 37, 151-184, doi:10.1016/ S0924-7963(02)00200-2.

—, and — 2007: Multiple jets of the Antarctic Circumpolar Current south of Australia. J. Phys. Oceanogr., 37, 1394-1412, doi:10.1175/JPO3111.1.

, and - 2009a: Circumpolar structure and distribution of the Antarctic Circumpolar Current fronts: 1 . Mean circumpolar paths. J. Geophys. Res., 114, C11018, doi:10.1029/ 2008JC005108.

$\longrightarrow$, and $-2009 \mathrm{~b}$ : Circumpolar structure and distribution of the Antarctic Circumpolar Current fronts: 2. Variability and relationship to sea surface height. J. Geophys. Res., 114, C11019, doi:10.1029/2008JC005248.

Ssalto/Duacs, 2014: Ssalto/Duacs gridded sea level anomalies. Copernicus Marine and Environment Monitoring Services, accessed 25 November 2015. [Available online at http:// marine.copernicus.eu/web/69-interactive-catalogue.php.]

Sura, P., and S. T. Gille, 2010: Stochastic dynamics of sea surface height variability. J. Phys. Oceanogr., 40, 1582-1596, doi:10.1175/2010JPO4331.1.

Tarakanov, R. Y., and A. Gritsenko, 2014: Fine-jet structure of the Antarctic Circumpolar Current south of Africa. Oceanology, 54, 677-687, doi:10.1134/S0001437014050130.

Thompson, A. F., 2010: Jet formation and evolution in baroclinic turbulence with simple topography. J. Phys. Oceanogr., 40, 257-278, doi:10.1175/2009JPO4218.1.

_ , and K. J. Richards, 2011: Low frequency variability of Southern Ocean jets. J. Geophys. Res., 116, C09022, doi:10.1029/2010JC006749.

_ _ and J.-B. Sallée, 2012: Jets and topography: Jet transitions and the impact on transport in the Antarctic Circumpolar Current. J. Phys. Oceanogr., 42, 956-972, doi:10.1175/ JPO-D-11-0135.1.

, P. H. Haynes, C. Wilson, and K. J. Richards, 2010: Rapid Southern Ocean front transitions in an eddy-resolving ocean GCM. Geophys. Res. Lett., 37, L23602, doi:10.1029/ 2010GL045386.

Volkov, D. L., and V. Zlotnicki, 2012: Performance of GOCE and grace-derived mean dynamic topographies in resolving Antarctic Circumpolar Current fronts. Ocean Dyn., 62, 893-905, doi:10.1007/s10236-012-0541-9.

Williams, R. G., C. Wilson, and C. W. Hughes, 2007: Ocean and atmosphere storm tracks: The role of eddy vorticity forcing. J. Phys. Oceanogr., 37, 2267-2289, doi:10.1175/JPO3120.1. 